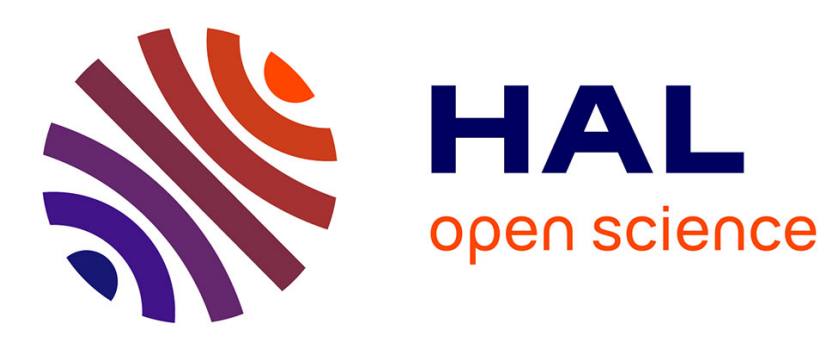

\title{
Upscaling of Elastic Properties in Carbonates: A Modeling Approach Based on a Multiscale Geophysical Data Set
}

Cedric Bailly, J. Fortin, M. Adelinet, Y. Hamon

\section{- To cite this version:}

Cedric Bailly, J. Fortin, M. Adelinet, Y. Hamon. Upscaling of Elastic Properties in Carbonates: A Modeling Approach Based on a Multiscale Geophysical Data Set. Journal of Geophysical Research: Solid Earth, 2019, 124 (12), pp.13021-13038. 10.1029/2019JB018391 . hal-02516786

\section{HAL Id: hal-02516786 \\ https: / hal-ifp.archives-ouvertes.fr/hal-02516786}

Submitted on 25 Mar 2020

HAL is a multi-disciplinary open access archive for the deposit and dissemination of scientific research documents, whether they are published or not. The documents may come from teaching and research institutions in France or abroad, or from public or private research centers.
L'archive ouverte pluridisciplinaire HAL, est destinée au dépôt et à la diffusion de documents scientifiques de niveau recherche, publiés ou non, émanant des établissements d'enseignement et de recherche français ou étrangers, des laboratoires publics ou privés. 
3 C. Bailly ${ }^{1,2}$, J. Fortin ${ }^{2}$, M. Adelinet ${ }^{1}$ and Y. Hamon ${ }^{1}$

$4{ }^{1}$ IFP Energies nouvelles, Direction Géosciences, 1 et 4 Avenue de Bois-Préau, 92852 Rueil-Malmaison

5 Cedex, France

$6 \quad{ }^{2}$ Laboratoire de Géologie, Ecole normale supérieure/CNRS UMR8538, PSL Research University, Paris

7 75005, France

8 Corresponding author: Cédric Bailly (bailly@geologie.ens.fr)

\section{Key Points:}

10 - Acquisition of multi-scale P-wave velocities at seismic, sonic and ultrasonic frequencies from the

11 field to the lab at a single study site

12 - P-wave velocity decrease from ultrasonic to seismic frequencies with an increasing representative

13 elementary volume

14 - Crack/fracture porosity control on the P-wave velocity at sonic and seismic scales leads to loss of 15 matrix porosity control 
Abstract

Linking ultrasonic measurements made in the laboratory on samples, with sonic logs and seismic

19 subsurface data is a key challenge for the understanding of carbonate reservoirs. To deal with this problem,

20 we investigate the elastic properties of dry lacustrine carbonates. At one study site, we perform a seismic

21 refraction survey $(100 \mathrm{~Hz})$, as well as "sonic" (54 kHz) and ultrasonic $(250 \mathrm{kHz})$ measurements directly on

22 outcrop and ultrasonic measurements on samples in the laboratory (500 kHz). By comparing the median of

23 each dataset, we show that the P-wave velocity decreases from laboratory to seismic scale. Nevertheless,

24 the median of the sonic measurements acquired on outcrop surfaces seem to fit with the seismic data,

25 meaning that sonic acquisition may be representative of seismic scale. To explain the variations with

26 upscaling, we relate the concept of Representative Elementary Volume (REV) with the wavelength of each

27 scale of study. Indeed, the wavelength varies from millimetric at ultrasonic scale to pluri-metric at seismic

28 scale. This change of scale allows us to conclude that the behavior of P-wave velocity is due to different

29 geological features (matrix porosity, cracks, fractures) related to the different wavelengths used. Based on

30 effective medium theories, we quantify the pore aspect ratio at sample scale and the crack/fracture density

31 at outcrop and seismic scales using a multi-scale REV concept. Results show that the matrix porosity that

32 controls the ultrasonic P-wave velocities is progressively lost with upscaling, implying that crack and

33 fracture porosity impacts sonic and seismic P-wave velocities, a result of paramount importance for seismic

34 interpretation based on deterministic approaches. 


\section{Introduction}

For isotropic rocks in dry conditions, upscaling of elastic properties can be done on the assumption that the velocity acquired at ultrasonic $(\mathrm{MHz})$, sonic $(\mathrm{kHz})$ and seismic $(\mathrm{Hz})$ frequencies are the same. Indeed, if the investigated porous medium is homogeneous and dry, it is theoretically not dispersive, i.e. the velocity does not depend on the frequency (Bourbié et al., 1987). This assumption is widely used in the literature (e.g. Wang et al., 1991; Marion and Jizba, 1997; Baechle et al., 2005; Adam et al., 2006; Verwer et al., 2008; Adelinet et al., 2011; Regnet et al., 2015 Borgomano et al., 2017) for inferring frequency dispersion of elastic wave velocity in homogeneous porous and fluid saturated rocks.

This equality of dry elastic moduli at all frequencies is only valid if the Representative Elementary Volume is uniform at each investigated scale (REV: volume of rock for which a physical property is constant, e.g. Bear, 1972), in other words if a rock is homogeneous at all scales. As outlined by Corbett (2009), this statement is far from true in geological medium which present "multiple length scales and multiple scales of homogenization". Indeed, following the conceptual geological scales of Haldorsen and Lake (1984), several scales of geological heterogeneities exist (Figure 1a), including : i) the microscopic scale (i.e. pore scale, $\mu \mathrm{m}$ to $\mathrm{mm}$ ); ii) the macroscopic scale (i.e. the plug scale, $\mathrm{cm}$ ); iii) the megascopic scale (i.e. outcrop scale, $\mathrm{m}$ to $\mathrm{dm}$ ) until iv) the gigascopic scale (i.e. regional scale, $\mathrm{km}$ ).

These different geological scales imply different heterogeneities that may impact the upscaling of the 54 elastic properties of rocks. This point is of importance for the characterization of reservoirs based on a deterministic approach, i.e. the use of velocity-porosity relationships based on laboratory and/or well data (e.g. Wyllie et al., 1956; Raymer et al., 1980; Anselmetti and Eberli, 1993) for inferring petrophysical 57 properties (like porosity) from seismic data through impedance inversion (e.g. Marion and Jizba, 1997; 58 Cichostępski et al., 2019). Indeed, as outlined by Wollner and Dvorkin (2018), a rock-physics model built

59 from a given scale (i.e centimetric in the laboratory) may not be applicable to another scale (i.e. pluri-metric 60 at seismic). According to Matonti et al. (2015), the direct comparison of P-wave velocities acquired on 61 carbonates at two different scales (plug versus outcrop) highlights a decrease of the P-wave velocity with 


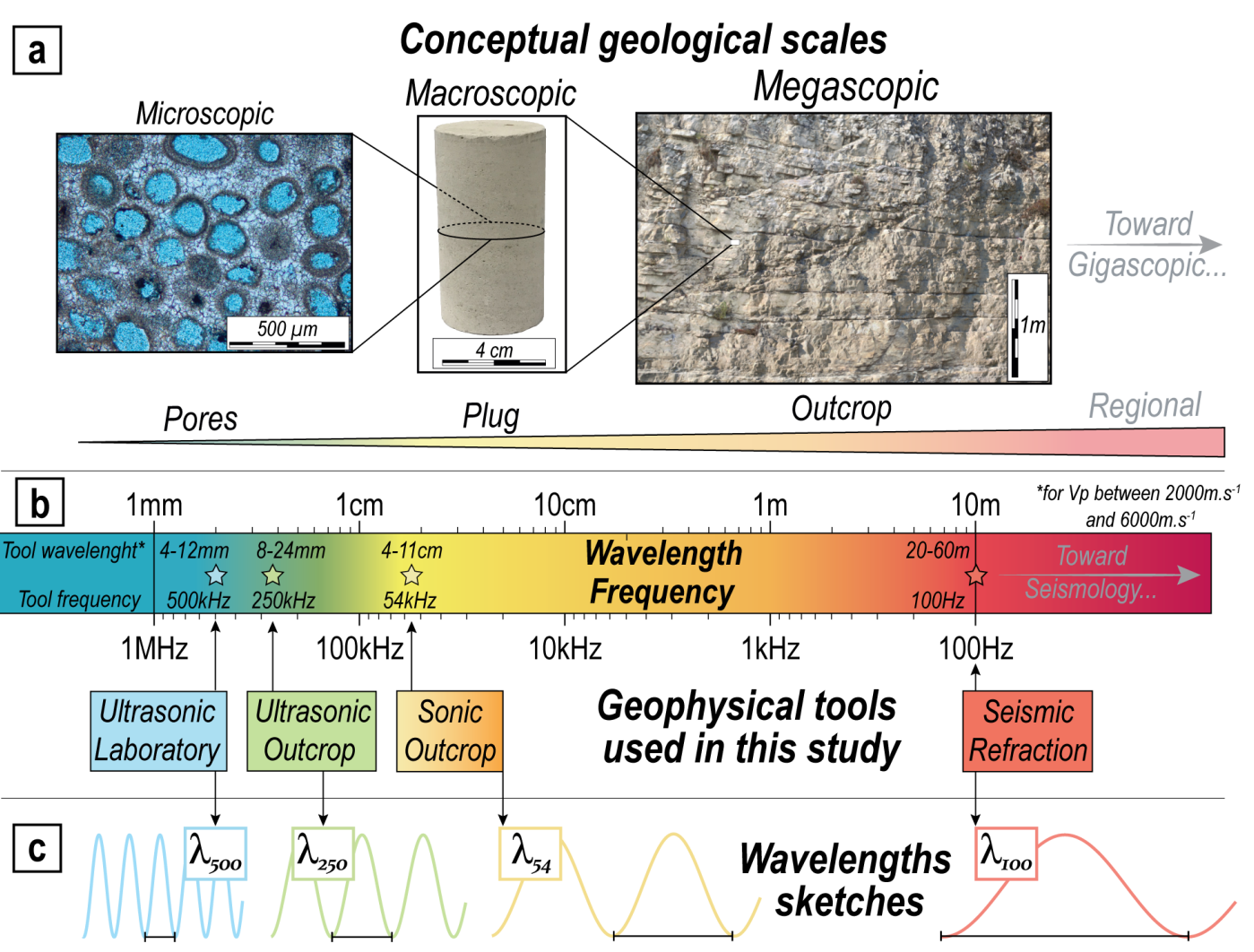

Figure 1. Comparison between upscaling in geology and geophysics. (a) Conceptual geological scales (from Haldorsen and Lake, 1984), highlighting the different scales of heterogeneities, including microscopic scale (pore size), macroscopic scale (plug size), megascopic (outcrop size) toward gigascopic scale (i.e. regional scale). (b) Frequencies and wavelengths for an elastic wave propagating at ultrasonic, sonic and seismic scales at a velocity of $1000 \mathrm{~m} \cdot \mathrm{s}^{-1}$. The four different scales investigated in the present study are highlighted in different colored stars. They are associated with their frequencies and wavelengths for a P-wave velocity ranging between 2000 and $6000 \mathrm{~m} \cdot \mathrm{s}^{-1}$. (c) Wavelength sketches of the four different scales studied on this work.

Indeed, a P or S wave velocity measurement is representative of the elastic properties at a scale close to the wavelength. On one hand, seismic measurements (low frequency, $f$, and thus large wavelength $-\lambda=\mathrm{c} / f$, where $\mathrm{c}$ is the velocity of the wave - in the order of several meters) will tend to erase small scale heterogeneities (Sheriff, 2002) (Figure 1b,c). On the other hand, ultrasonic measurements (high frequency, small wavelength) on samples are representative of the elastic properties at a scale of the order of the 
81 millimeter (Figure 1b,c). Using a multi-scale geophysical dataset, it is thus possible to relate the elastic

82 properties acquired at different frequencies, and so defining effective elastic properties at different scales

83 of investigation. This purpose follows the previous works of Nordahl \& Ringrose (2008) and Ringrose et

84 al. (2008) who argued that a multiscale geological medium has to be related to multiscale REVs. A

85 fundamental challenge here is to measure elastic properties of the same geological object across all scales

86 (Corbett, 2009). To do so, we study Miocene lacustrine carbonates from Samos Island (Greece).

87 We measure their dynamic elastic properties using several geophysical tools at different scales, from

88 field to laboratory (Figure 1): seismic refraction method ( $100 \mathrm{~Hz})$, sonic/ultrasonic measurements directly

89 on outcrop $(54 \mathrm{kHz}$ and $250 \mathrm{kHz})$, and ultrasonic measurements on plugs (500 kHz). These measurements

90 enable us to link and discuss the impact of different geological features (such as pores, cracks and fractures)

91 on the measured P-wave velocities from millimetric scale to decametric scales. Finally, based on asymptotic

92 approximations of Differential Elementary Medium scheme (DEM, David and Zimmerman, 2011a,b), we

93 compare the multi-scale elastic properties of the studied carbonates using a concept of multi-scale REVs

94 that take into account different scales of heterogeneities. In the following manuscript, the terms "cracks"

95 and "fractures" will refer to the occurrence and modeling of very low aspect ratio inclusions isotropically

96 distributed.. The cracks correspond to small-scale inclusions ( $\mathrm{mm}$ to $\mathrm{cm}$ scale) while the fractures are

97 attributed to large-scale inclusions (dm to m scale).

98

\section{2. Study framework}

100 Our study is focused on lacustrine carbonates of Samos, a Greek island located on the eastern part of the

101 Aegean Sea, near Turkey (Figure 2a). This island presents two sedimentary basins in which lacustrine

102 sedimentation occured during the Upper Miocene (Weidman et al., 1984). Figure 2b points out the study

103 site on which we perform a seismic survey together with an outcrop description (Figure $2 \mathrm{c}$ ). This study site

104 is localized on the Mytilini Basin, infilled with a huge diversity of rocks (such as volcaniclastic, siliciclastic

105 and carbonate rocks, Figure 2d). Our study focuses on the topmost part of the Hora Formation composed 
of lacustrine and palustrine carbonates (Figure 2d). These carbonates are deposited right before a major

107 exposure, expressed as an erosional surface (Hora-Mytilini transition) according to Weidman et al. (1984)

108 and Stamatakis et al. (1989). This emergence may result from a tectonic uplift (compressive phase of Ring

109 et al., (1999)) and/or an increase in aridity causing a global drying of the lake (Owen et al., 2011).
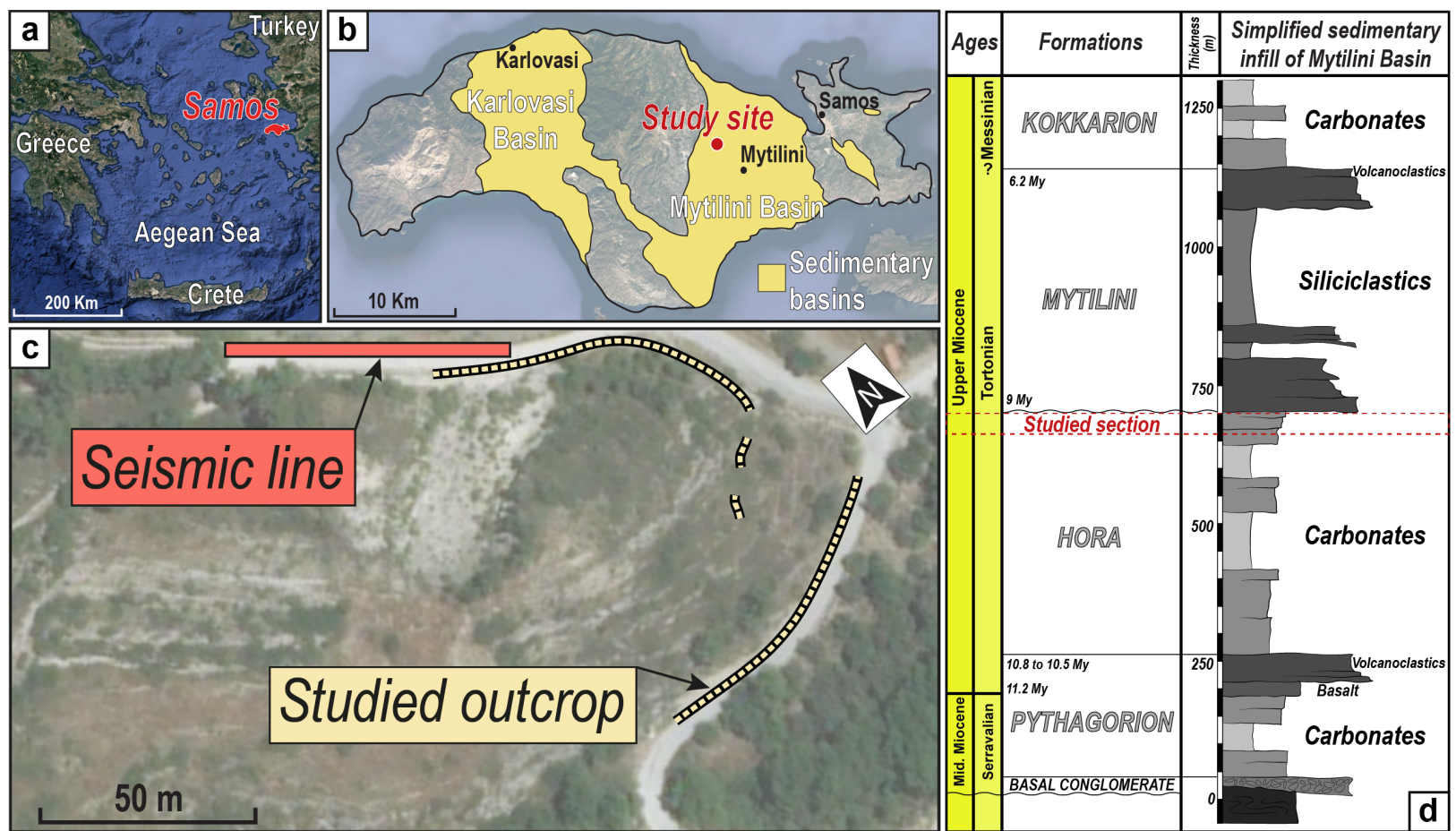

Figure 2. General framework: (a) Location of Samos Island in the Aegean Sea. (b) Sedimentary basins of Samos Island and location of the study area (N3744'21”; E26 $\left.53^{\prime} 45^{\prime \prime}\right)$. (c) GoogleEarth $\odot$ view of the study area showing the studied outcrop and the location of the seismic line. (d) Stratigraphic column modified after Weidmann et al. (1984) showing the sedimentary infill of Mytilini Basin divided into four lithostratigraphic formations. The stratigraphic location of our studied section is highlighted in red. 


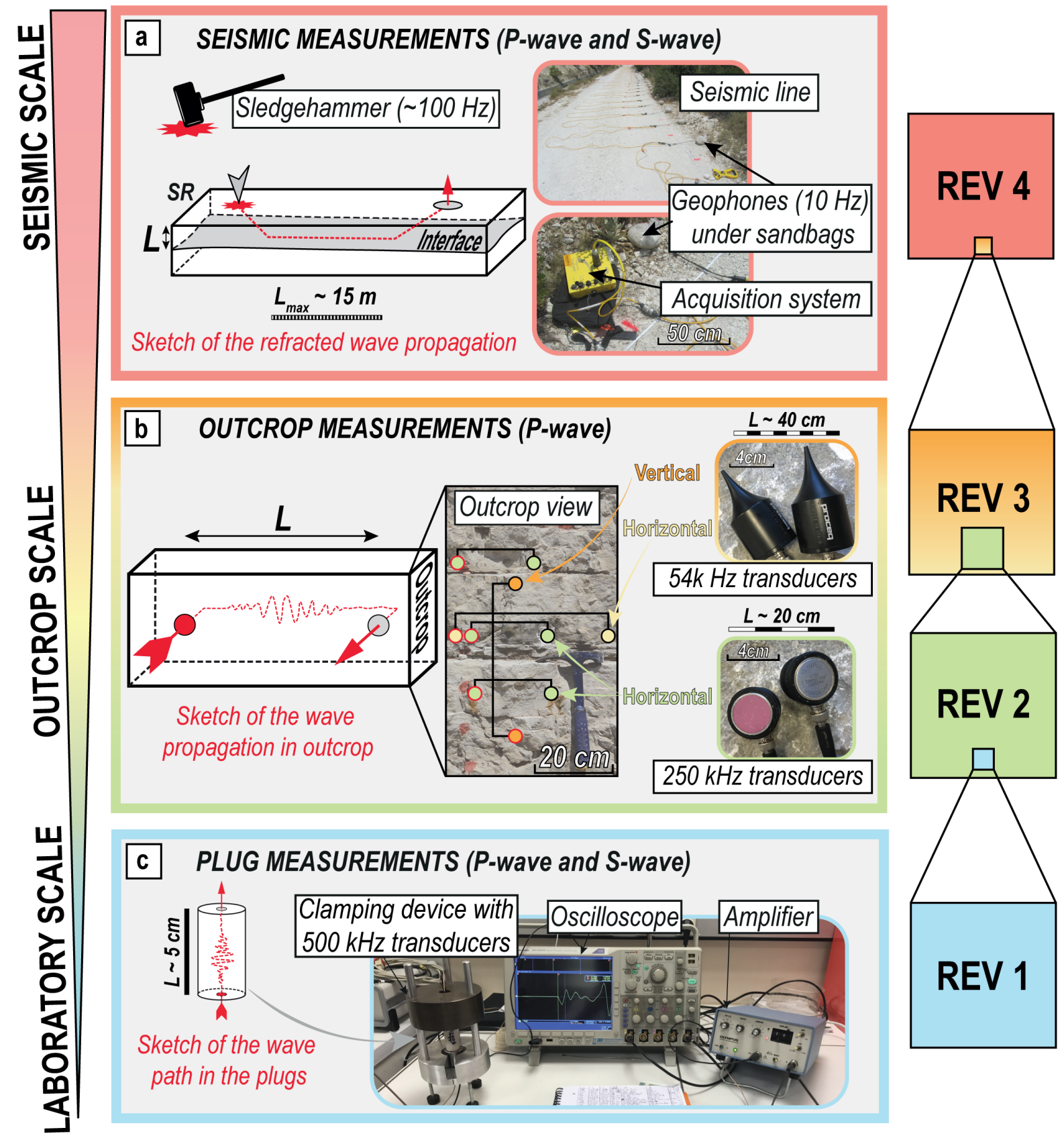

120 Figure 3. Applied methodology for this work and corresponding relative evolution of the Representative 121 Elementary Volume (REV): (a) Seismic measurements. On the left, sketches of the refracted wave 122 propagation (SR) produced by a sledgehammer source. The acquisition system (DAQLINK IV and 123 geophones) and a field view of the seismic line are indicated on the right. (b) Outcrop measurements. On the left, sketch of the wave propagation in outcrop (with L corresponding to the covered distance). On the middle, outcrop view in reality with examples of the transducer positions during measurements. On the right, $250 \mathrm{kHz}$ and $54 \mathrm{kHz}$ transducers used for P-wave acquisitions. (c) Plug measurements. On the left, sketch of the wave propagation in plug (average length of $5 \mathrm{~cm}$ ). On the right, acquisition device used for $\mathrm{P}$-wave and S-wave measurements. 


\section{Multi-scale methodology}

The study site enabled us to acquire acoustic measurements at different scales while keeping a geological control thanks to the outcrop. The frequencies of the different tools used in this work are summarized in Figure 1 and are paired with their wavelengths. A thorough description of this multi-scale geophysical methodology is highlighted in Figure 3. All the acoustic measurements presented in this work were acquired under dry conditions. The field campaign was carried out during the end of June 2018, with an average temperature of $25^{\circ} \mathrm{C}$ and an average humidity of $70 \%$. Last rainfall occurred 2 days before the measurements, with an amount of water lower than $0.3 \mathrm{~mm}$.

\subsection{Outcrop characterization \& sampling}

A sedimentary description of a $40 \mathrm{~m}$ thick sedimentary succession was undertaken ('Studied outcrop',

144 Figure 2c) alongside a high-resolution sampling in order to acquire physical properties (one sample every $14520 \mathrm{~cm}$ along a vertical section). Depending on the sample size, plugs were cored with a diameter of $23 \mathrm{~mm}$ 146 for 81 samples and $40 \mathrm{~mm}$ for 20 samples. Furthermore, panorama pictures aim to highlight outcropping 147 structural features (e.g. bedding planes, fractures and faults), showing the structural heterogeneity at outcrop 148 scale (Figure 4).

\subsection{Seismic refraction acquisition} sound source is a $4 \mathrm{~kg}$ sledge-hammer striking a Teflon plate (central frequency of $100 \mathrm{~Hz}$, Figure 1). Fortyeight geophones with a natural frequency of $10 \mathrm{~Hz}$ were regularly spread along a line with a $1 \mathrm{~m}$-spacing and recorded the wave acceleration (Figure 3a). They were covered with sandbags to ensure a good coupling

156 with the ground and limit the ambient noise. Seven shots were done along the seismic line. In order to 
157 increase the signal/noise ratio of the recorded waveforms we stacked three times each shot (21 hammer

158 strikes). Refraction processing was then done using Pickwin and Plotrefra software packages from

159 SeisImager, following the processing used by Adelinet et al. (2018). The seismic refraction processing only

160 allowed us to characterize an increase in P-wave velocity with depth. This method provides a wavelength

161 in the range of $20-60 \mathrm{~m}$ (decametric wavelength of Figure 1) that offer the opportunity to characterize a

162 large REV (REV 4 of Figure 3).

\subsection{Outcrop acoustic measurements}

While the seismic refraction survey was carried out at the top of the outcrop (Figure 2c), P- wave velocities were directly measured on the outcrop surface using a Pundit PL-200 (Jeanne et al., 2012; Matonti et al., 2015) and two types of transducers (Figure 3c). To probe alteration of the outcrop, freshening of the rock surface was done with a hammer. The travel-time (first break) was directly pointed out on the oscillograph and the P-wave velocity is obtained by using the total distance travelled (L of Figure 3). The

171 measurements were obtained with a high vertical sampling (one measurement every $20 \mathrm{~cm}$ ) and two 172 different spacings between the receiver and transmitters. The $54 \mathrm{kHz}$ transducer were used for measuring 173 P-wave velocity with a spacing of $40 \mathrm{~cm}$ between the transducers and two kinds of measurements: i) a 174 vertical transect (orange points of Figure 3b) and ii) a horizontal transect (yellow points of Figure 3b). In 175 parallel, the $250 \mathrm{kHz}$ transducers allowed the measurements of P-wave velocity with a spacing of $20 \mathrm{~cm}$ 176 along a horizontal transect (green points of Figure 3b). The peak shape of the $54 \mathrm{kHz}$ transducers made it 177 possible to perform measurements without a coupling gel. However, coupling gel was used for the $250 \mathrm{kHz}$ 178 transducers (Sonctec 54-T04). For the spacing between the transducers, we assume an error of $1 \mathrm{~cm}$. The 179 travel-time error is lower than $5 \%$. The resulting mean errors are equal to $10 \%$ for the $54 \mathrm{kHz}$ and $250 \mathrm{kHz}$.

180 These sonic $(54 \mathrm{kHz})$ and ultrasonic $(250 \mathrm{kHz})$ outcrop measurements give us centimetric and millimetric 181 wavelengths (Figure 1) that offer the opportunity to characterize the intermediate length scale (REVs 3 and 1822 of Figure 3). 
Measurements were done in the laboratory on samples cored blocks coming from the outcrop.

Porosity and density of 101 were measured with the Archimedes' method (plug mass obtained under three

187 conditions: dry, fluid-saturated and suspended in the saturating-fluid). P- and S- ultrasonic wave velocities

188 were obtained on oven-dry samples $\left(60^{\circ} \mathrm{C}\right.$ during 48 hours $)$ using $500 \mathrm{kHz}$ transducers connected to an 189 oscilloscope (Figure 3c). The arrival times of P-waves (first break) were directly measured on the 190 oscillograph and divided by the length of samples to calculate P-wave velocities. As indicated by Bailly et 191 al. (2019), the error of this dataset is mainly related to the first break picking (lower than $5 \%$ ). Ultrasonic 192 measurements provide millimetric wavelengths that are used to characterize the smaller scale (REV 1 of 193 Figure 3).

\subsection{Kernel smoothing}

We applied non-parametric Kernel regressions to smooth the vertical trends of the P-wave velocities acquired at plug and outcrop scales. Then, based on the standard error measured on the smoothed curves, a calculation of the $95 \%$ confidence interval was done using R software.

\section{Results : Multi-scale dataset, from megascopic scale to microscopic scale}

\subsection{Structural features at outcrop}

Figure 4 highlights the studied section and a thorough description of the observed structural

206 features. The mapping of bedding planes (horizontal black lines) outlines a highly stratified pattern that is 207 laterally and vertically persistent (around 3 bedding planes per meter). Furthermore, stratabound and non208 stratabound fractures (vertical red lines, around 8 per meter) affect beds, overprinting the horizontal 
210 planes.

211
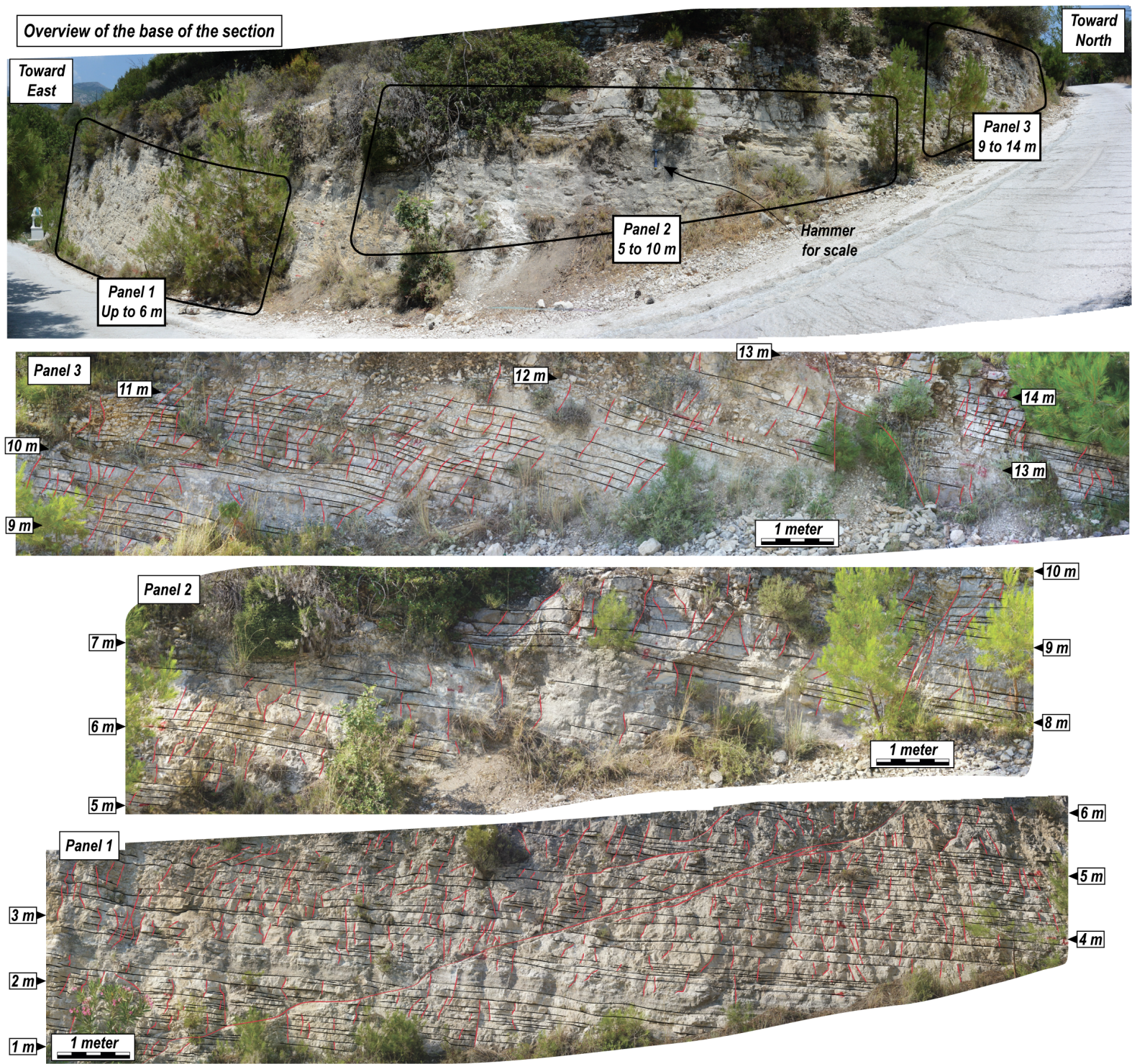

Figure 4. Outcrop view highlighting the presence of bedding planes (in dark), fractures and faults (in red).

\subsection{Seismic refraction dataset, a $2 D$ characterization of elastic properties}

Figure 5 presents the P-wave velocity profile obtained after inversion (seismic line of Figure 2a).

219 The topography is nearly flat. The first meter of depth correspond to a P-wave velocity equal or lower than 
$2201200 \mathrm{~m} \cdot \mathrm{s}^{-1}$. Then, the P-wave velocity quickly increases up to $2000 \mathrm{~m} \cdot \mathrm{s}^{-1}$ between 2 to 5 meters of depth, 221 depending on the horizontal location. Finally, P-wave velocity increases more slowly, up to $2400 \mathrm{~m} . \mathrm{s}^{-1}$ 222 between 5 to 10 meters depth depending also on the horizontal localization.

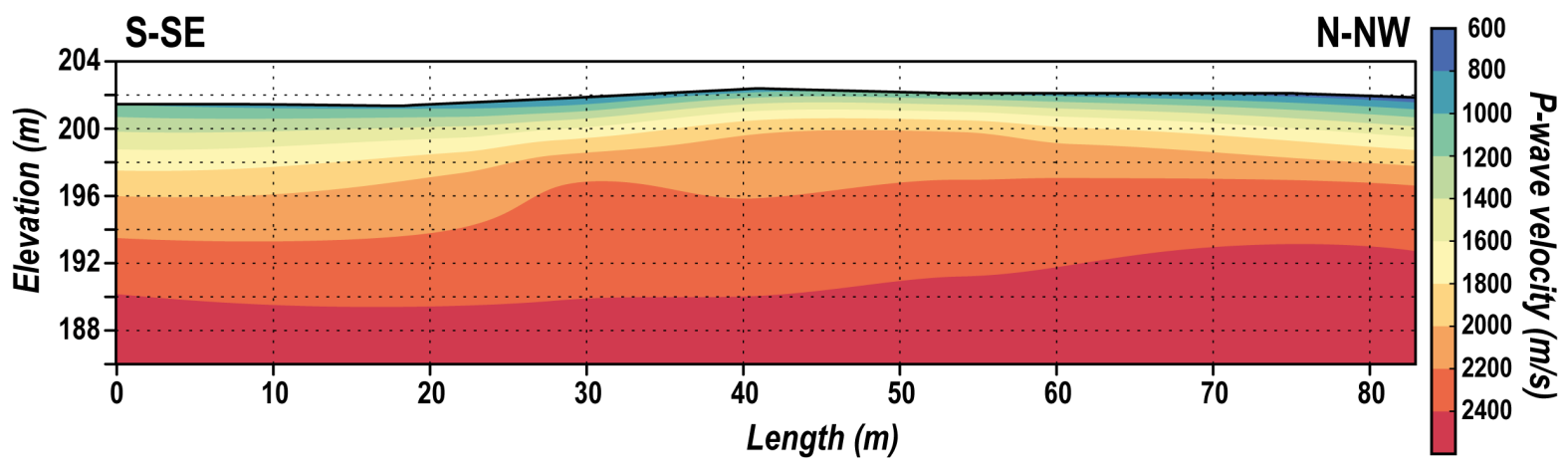

223

224

225

226

227

228

229

230

231

232

233

234

235

\subsection{Log dataset, a $1 D$ vertical evolution of P-wave velocities}

Figure 6a introduces the sedimentary log described on the field and the associated physical measurements acquired at multi-scale. The 40 meters thick sedimentary column exhibits mainly carbonate rocks. The lower part of the sedimentary column shows muddy and grainy carbonates with episodic exposure surfaces associated with pedogenesis (between 0 and 14 meters). Because of the vegetation cover, a part of the sedimentary succession has not been studied between 23 and 29 meters; we recognize some metric beds of grainy carbonates. Then, the top of the sedimentary section highlights again grainy and muddy carbonates alternating with beds of marls (between 32 and 40 meters). Note that Bailly et al. (2019) give a more detailed description of the studied outcrop.

of the outcrop up to $5 \mathrm{~m}$, porosities between $10 \%$ and $25 \%$ are observed and the associated smooth curves don't show an obvious vertical evolution. Then, between 5 and $14 \mathrm{~m}$, the porosity presents higher values (up to $35 \%$ ) and lower values (down to $5 \%$ ) as well as some noticeable vertical fluctuations (metric 
242 decrease and increase of porosity). Then, between 24 and $30 \mathrm{~m}$, the smooth curve does not a show

243 significant vertical evolution of porosity (average value of 10-15\%). Between 32 and 36 m, porosity

244 decreases from $25 \%$ down to $5 \%$. Finally, the last part of the sedimentary column exhibits higher values

245 of porosity centered around $20-25 \%$.

Beside the porosity curve, the P-wave velocity acquired on plug, outcrop and seismic scales are displayed. Vp p $_{500}$ (plug measurements) exhibits ultrasonic P-wave values between 2900 and 5600 m.s s $^{-1}$

249 (Figure 6c). Its metric vertical evolution is related to the porosity changes described above: when porosity increases, P-wave velocity decreases and vice versa (see also Figure 7b).

$\mathrm{Vp}_{250}$ (in-situ horizontal outcrop measurements) shows P-wave values between 1000 and $2535000 \mathrm{~m} \cdot \mathrm{s}^{-1}$ (Figure 6d), its fluctuations are higher than $\mathrm{Vp}_{500}$. From the base of the outcrop up to $14 \mathrm{~m}$, the 254 smoothed curve associated with $\mathrm{Vp}_{250}$ presents metric fluctuations of $\mathrm{P}$-wave velocity with values centered 255 around 2000 and $4000 \mathrm{~m} \cdot \mathrm{s}^{-1}$ with values up to $4500 \mathrm{~m} \cdot \mathrm{s}^{-1}$ between 10 and 12 meters. Later, between 24 and

25630 meters, $\mathrm{Vp}_{250}$ presents obvious vertical fluctuations that were not recorded with $\mathrm{Vp}_{500}$. Between 32 and 25740 meters, $\mathrm{Vp}_{250}$ highlights meter-scale fluctuations with values up to $5000 \mathrm{~m} . \mathrm{s}^{-1}$ and down to $1000 \mathrm{~m} . \mathrm{s}^{-1}$.

$\mathrm{Vp}_{54 \mathrm{H}}$ (horizontal in-situ outcrop measurements) presents $\mathrm{P}$-wave values between 500 and $2604500 \mathrm{~m} \cdot \mathrm{s}^{-1}$ (Figure 6e). For the first part of the sedimentary column (0 to 14 meters), most of the vertical 261 fluctuations of $\mathrm{Vp}_{54 \mathrm{H}}$ are similar to $\mathrm{Vp}_{250}$, showing $\mathrm{P}$-wave velocity values centered around 2000 and $2623000 \mathrm{~m} \cdot \mathrm{s}^{-1}$. Then, between 24 and 30 meters, the fluctuations of $\mathrm{Vp}_{54 \mathrm{H}}$ mimic $\mathrm{Vp}_{250}$ with lower P-wave 263 velocity values (500 to $4000 \mathrm{~m} \cdot \mathrm{s}^{-1}$ ). Between 32 and 35 meters, $\mathrm{Vp} \mathrm{p}_{54 \mathrm{H}}$ presents a more chaotic vertical 264 fluctuation not similar to $\mathrm{Vp}_{250}$, with $\mathrm{P}$-wave velocity values comprised between 500 and $3500 \mathrm{~m} . \mathrm{s}^{-1}$.

$266 \quad \mathrm{Vp}_{54 \mathrm{~V}}$ (vertical in-situ outcrop measurements) presents P-wave values between 1000 and $2673500 \mathrm{~m} \cdot \mathrm{s}^{-1}$ (Figure 6f). Its vertical fluctuations are partly similar to $\mathrm{Vp}_{54 \mathrm{H}}$ (e.g. between 3 and 6 meters, 
268 around 25 and 28 meters, between 32 and 34 meters) but present a more chaotic fluctuation in the remaining 269 part of the sedimentary column.

270

Finally, $\mathrm{Vp}_{100}$ (seismic data) is also presented for comparison of the overall P-wave velocity dataset

272 on a vertical way (Figure $6 \mathrm{~g}$ ). Because of the vertical resolution, the lower part of the sedimentary column

273 is not imaged (non-visible zone in Figure 6g). As previously showed in Figure 5, the highest P-wave velocity

274 value of $\mathrm{Vp}_{100}$ is about $2400 \mathrm{~m} \cdot \mathrm{s}^{-1}$, reached between 25 and 28 meters. Then, between 28 and 37 meters,

$275 \mathrm{Vp}_{100}$ decreases linearly down to $2000 \mathrm{~m} \cdot \mathrm{s}^{-1}$. At the top of the sedimentary column (37 to 40 meters), $\mathrm{Vp}_{100}$

276 decreases drastically down to $800 \mathrm{~m} \cdot \mathrm{s}^{-1}$. 


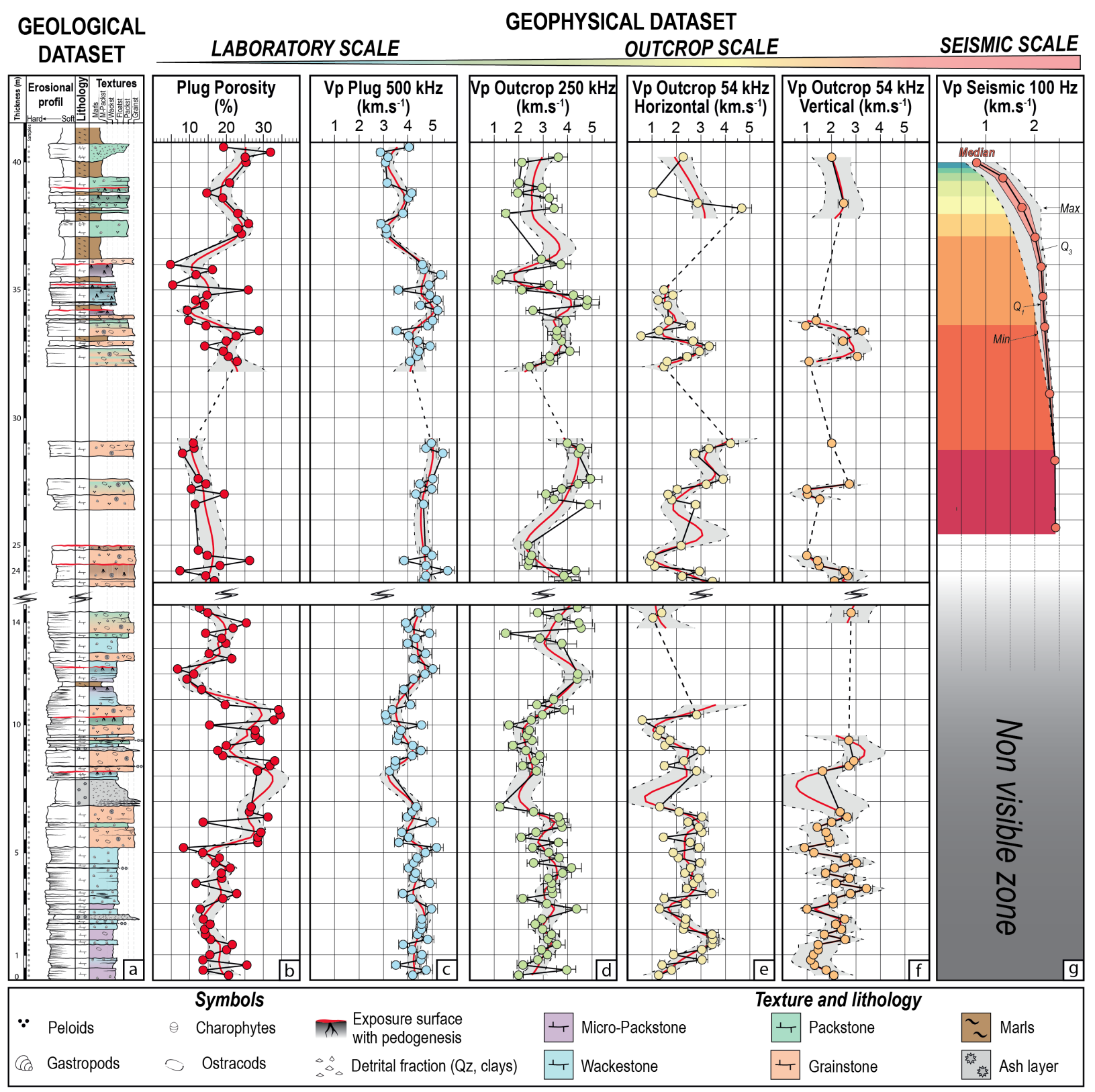

Figure 6. (a) Sedimentary log compared with vertical variations of (b) plug porosity and P-wave velocity acquired at (c) laboratory (500 kHz), (d) (e) and (f) outcrop (250 and $54 \mathrm{kHz})$ and (g) seismic (100 Hz) frequencies. Smooth curves with their $95 \%$ confidence interval are also indicated in order to describe the 


\subsection{Porosity-ultrasonic velocity relationship at plug scale}

Figure 7a shows the P- and S-wave velocities acquired on plugs. Vp $\mathrm{p}_{500}$ values range between 2800

290 and $5600 \mathrm{~m} . \mathrm{s}^{-1}$, while Vs500 values range between 1600 and $3100 \mathrm{~m} . \mathrm{s}^{-1}$. The $\mathrm{Vp}_{500}$ versus $\mathrm{Vs}_{500}$ plot exhibits

291 a good linear trend $\left(\mathrm{R}^{2}=0.89\right)$ that indicates a $\mathrm{Vp} / \mathrm{Vs}$ ratio equal to 1.84 , consistent for carbonate rocks

292 (assuming a Poisson ratio equal to the one of pure calcite, a ratio of $\mathrm{Vp} / \mathrm{Vs}=1.91$ is expected, Mavko et al., 293 2009).

Figure $7 \mathrm{~b}$ exhibits $\mathrm{Vp}_{500}$ versus porosity. It shows a clear decrease of velocities with an increase of 296 porosity. For explaining the scattering of velocities for a given porosity, we use the analytical expressions 297 of David and Zimmerman (2011b) that aims to compute the effective elastic properties of an isotropic solid 298 containing randomly oriented spheroidal pores. Thanks to this DEM model, we compute the aspect ratio $299(0.01<\alpha<0.3$, ratio between the longer and the shorter length of an ellipse) embedded in a pure calcite 300 medium $\left(\mathrm{Vp}_{\text {Calcite }}=6400 \mathrm{~m} \cdot \mathrm{s}^{-1}\right)$. The resulting mean pore aspect ratio is about $\alpha=0.16(\sigma=0.04)$, shows a 301 minimum of 0.04 and a maximum of 0.25 . These results about the aspect ratio in carbonate rocks are 302 consistent with previous studies (e.g. Fournier et al. (2018); Regnet et al. (2019a)). 

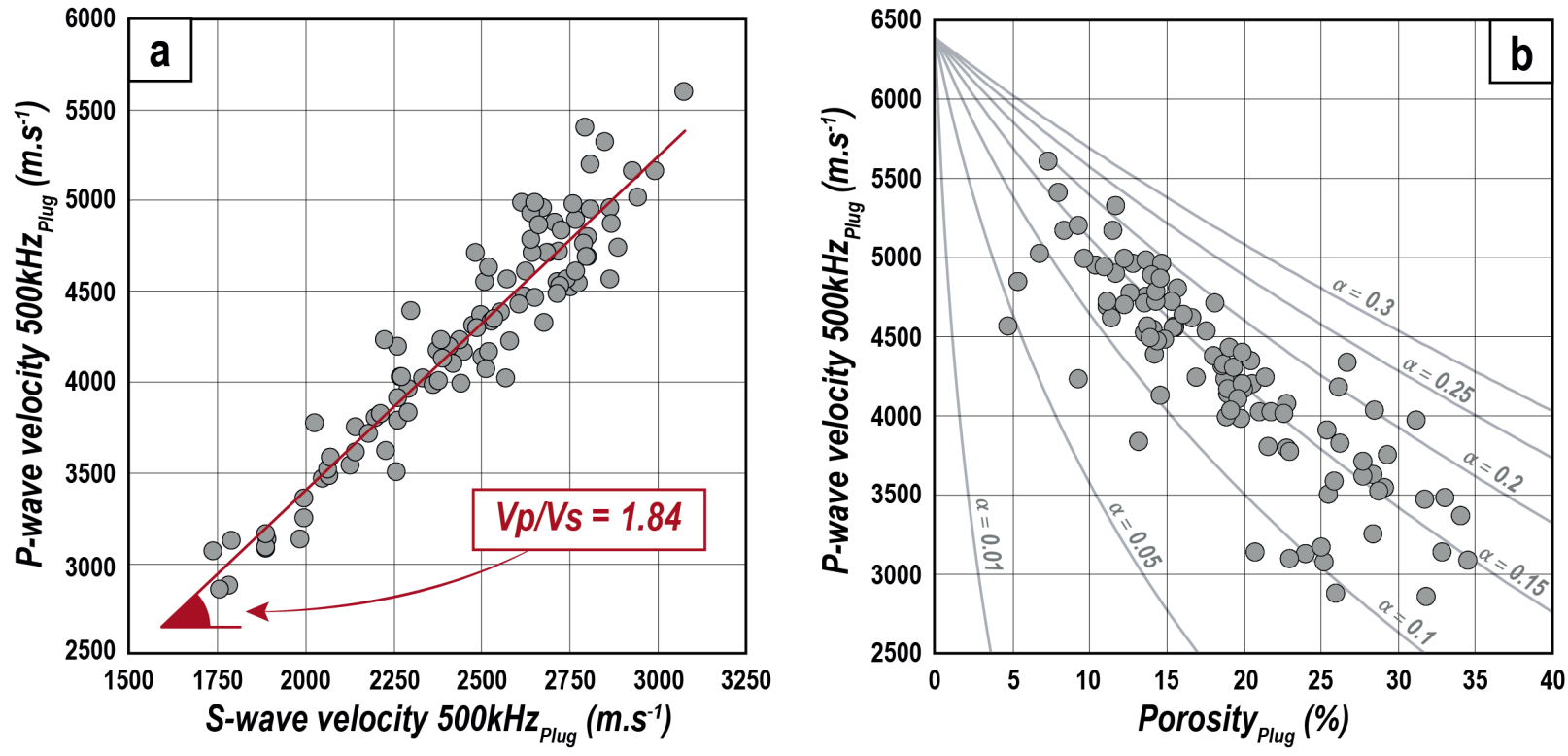

Figure 7. Plug data: (a) $\mathrm{Vp}_{500}$ versus $\mathrm{Vs}_{500}$ and associated trend (red line). (b) $\mathrm{Vp}_{500}$ versus porosity. Curves of constant aspect ratio of pores are indicated for a pure calcite matrix.

\subsection{Statistical distribution of the multi-scale P-wave velocity}

The boxplots, of each P-wave velocity dataset acquired in this work, are shown in Figure 8a. For $\mathrm{Vp}_{500}$, half of the dataset is comprised between 3800 and $4700 \mathrm{~m} \cdot \mathrm{s}^{-1}$, with a median of about $4300 \mathrm{~m} \cdot \mathrm{s}^{-1}$. Then, $\mathrm{Vp}_{250}$ displays lower values of velocity, with half of this dataset comprised between 2500 and 3800 $\mathrm{m} . \mathrm{s}^{-1}$, and a median of $3200 \mathrm{~m} \cdot \mathrm{s}^{-1}$. The interquartile of $\mathrm{Vp}_{54 \mathrm{H}}$ is comprised between values of 1500 and 2900 $\mathrm{m} . \mathrm{s}^{-1}$, and partly overlaps $\mathrm{Vp}_{250}$ with a median equal to $2300 \mathrm{~m} \cdot \mathrm{s}^{-1}$. V $\mathrm{p}_{54 \mathrm{~V}}$ completely overlaps $\mathrm{Vp}_{54 \mathrm{H}}$, with half of its values comprised between 1500 and $2600 \mathrm{~m} \cdot \mathrm{s}^{-1}$, and a median equal to $2000 \mathrm{~m} . \mathrm{s}^{-1}$. Finally, half of the values of $\mathrm{Vp}_{100}$ are comprised between 1700 and $2300 \mathrm{~m} \cdot \mathrm{s}^{-1}$, with a median of $2200 \mathrm{~m} . \mathrm{s}^{-1}$.

The normal laws of each dataset are shown in Figure 8b. Data acquired in the laboratory and outcrop exhibit a nearly symmetrical distribution (median $\approx$ mean). Contrarily, $\mathrm{Vp}_{100}$ shows an asymmetric distribution, (median $<$ mean). It has to be noted that $\mathrm{Vp}_{500}, \mathrm{Vp}_{54 \mathrm{~V}}$ and $\mathrm{Vp}_{100}$ show less scattering than $\mathrm{Vp}_{250}$ and $\mathrm{Vp}_{54 \mathrm{H}}$ (flattening of the curves). 


\section{Statistical distribution of P-wave velocity at all scales}
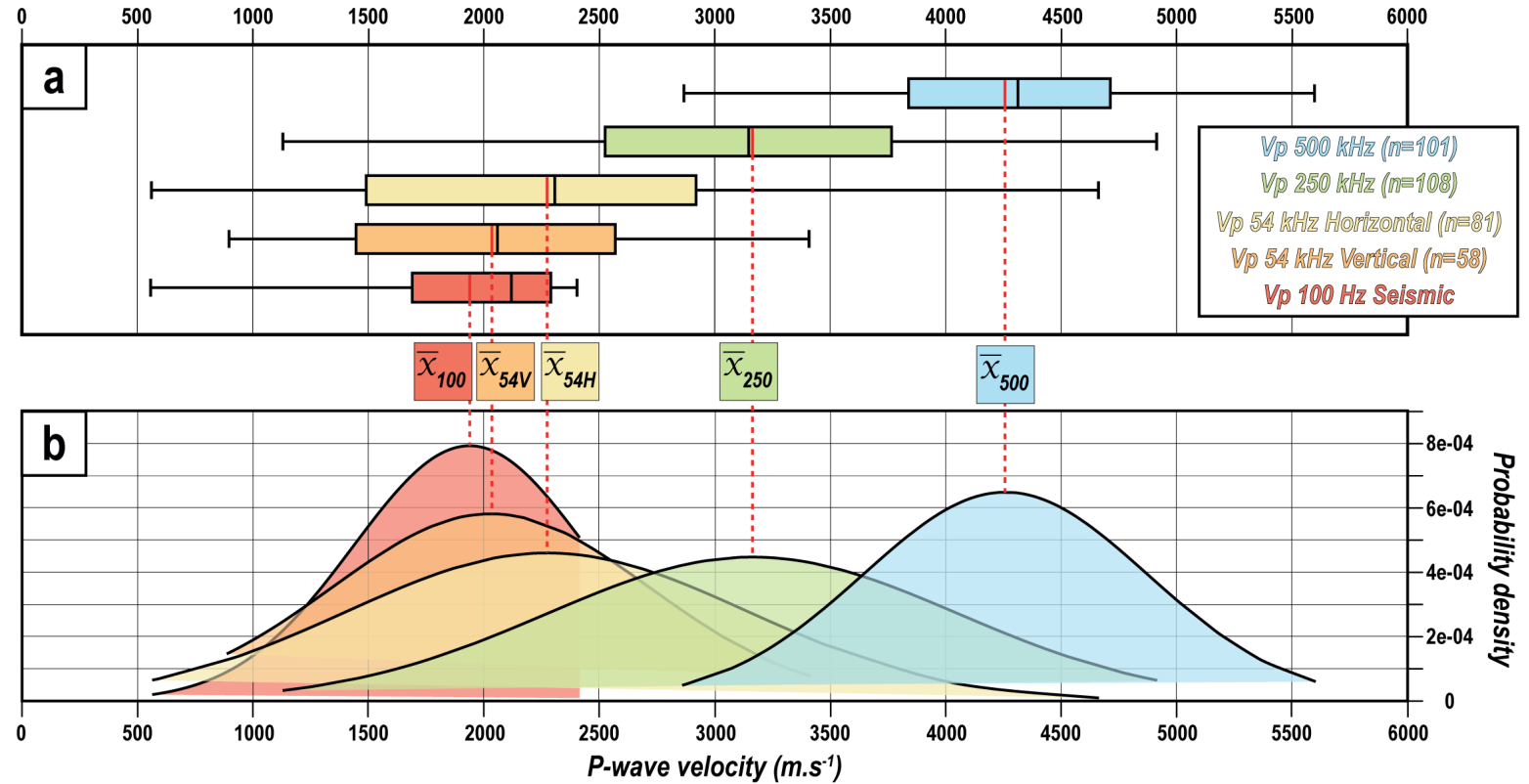

Figure 8. Statistical distribution of $\mathrm{P}$-wave velocities at all scales. (a) Boxplots of each dataset with mean indicated . (b) Normal laws of each data set, showing the difference of mean and standard deviation.

Figure 9 summarizes the descriptive statistics of P-wave velocity of each dataset (Figure 8a) versus their corresponding wavelength. In addition, the four curves of constant frequency induced by the different geophysical tools are plotted. An overall decrease of P-wave velocity is observed, from ultrasonic to seismic frequency (Figure 9). This shift of P-wave velocity is particularly well-defined by the interquartile domain and the median of each dataset. The main decline of the P-wave velocity is observed between $\mathrm{Vp}_{500}$ and

$331 \mathrm{Vp}_{54 \mathrm{H}}$, with a decrease of about $2000 \mathrm{~m} \cdot \mathrm{s}^{-1}$, associated with an increase of the wavelength size, from 6-

$33210 \mathrm{~mm}$ for $\lambda_{500}$ to $2-6 \mathrm{~cm}$ for $\lambda_{54}$. Then, between $\mathrm{Vp}_{54}$ and $\mathrm{Vp}_{100}$, the P-wave velocity decreases to a lesser 333 extent (decrease of $200 \mathrm{~m} . \mathrm{s}^{-1}$ ) despite that, the associated wavelength increases from 2-6 $\mathrm{cm}$ for $\lambda_{54}$ to $\sim 20 \mathrm{~m}$ 334 for $\lambda_{100}$. This last result (comparison between $\mathrm{Vp}_{54}$ and $\mathrm{Vp}_{100}$ ) suggests that the elastic properties 335 characterized at a sonic frequency are representative of elastic properties acquired at seismic frequency, at 336 least for the study site that we investigate. 


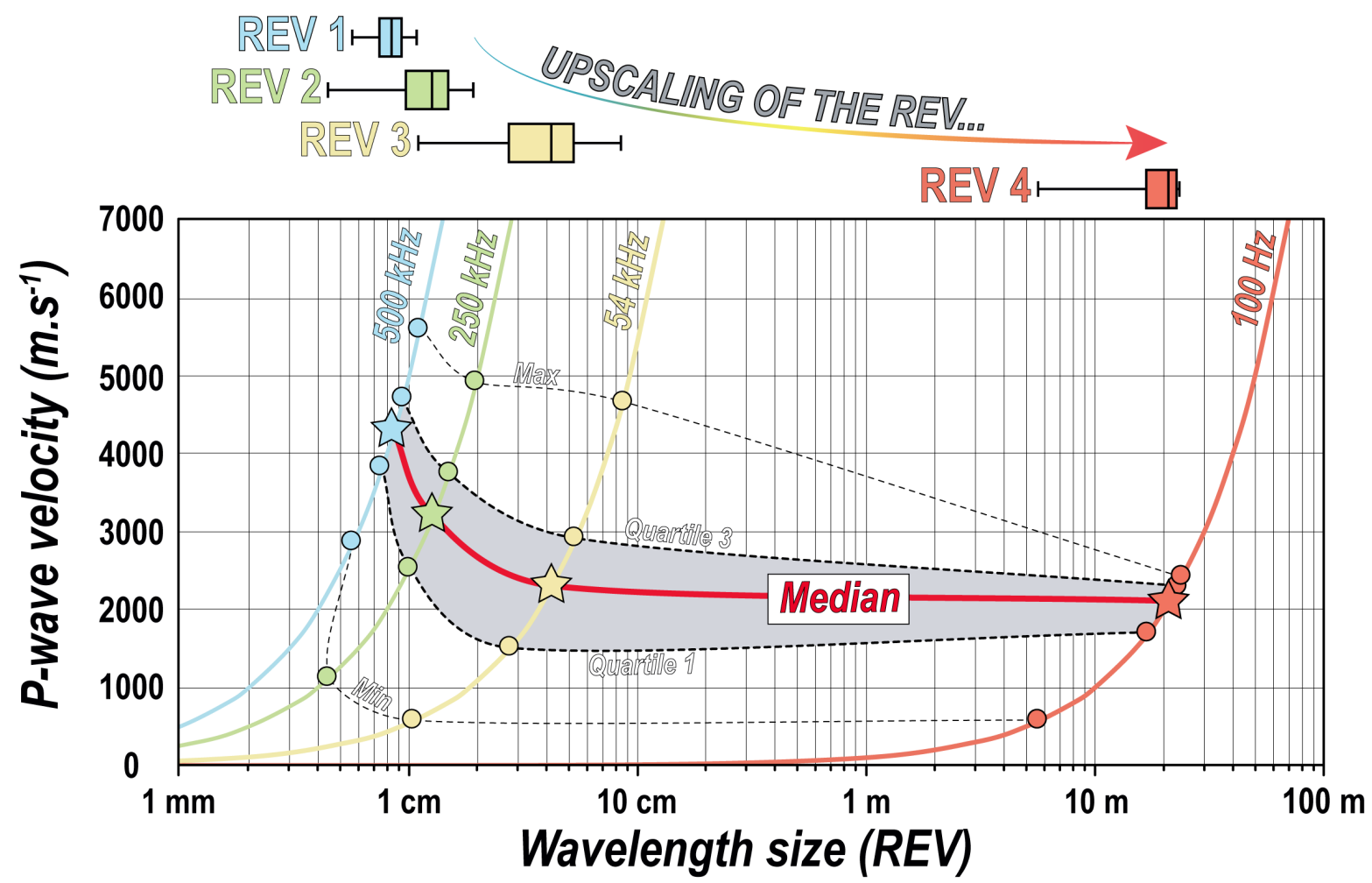

Figure 9. P-wave velocities of four datasets versus wavelength size (REV). Only the descriptive statistics of P-wave velocity and wavelength are displayed. The grey area corresponds to the interquartile range and the red curve shows the median. Curves of constant frequency are also indicated. Boxplots showing the evolution of the wavelength with scale are displayed on the top.

The descriptive statistics of P-wave velocity of each dataset can be also investigated through probability density maps (PDM, Figure 10). In Figure 10a, most of the dataset exhibits $\mathrm{Vp}_{500}$ higher than $\mathrm{Vp}_{250}$ even if a few data points are located close to the line of equality. The highest values of PDM indicate $\mathrm{Vp}_{500}$ between 4000 and $5000 \mathrm{~m} \cdot \mathrm{s}^{-1}$ while $\mathrm{Vp}_{250}$ scatters between 2000 and $4500 \mathrm{~m} . \mathrm{s}^{-1}$. This observation is further reinforced by Figure $10 \mathrm{~b}$, showing $\mathrm{Vp}_{500}$ always higher than $\mathrm{Vp}_{54 \mathrm{H}}$. Again the highest values of PDM suggests $\mathrm{Vp}_{500}$ between 4000 and $5000 \mathrm{~m} . \mathrm{s}^{-1}$ while $\mathrm{Vp}_{54}$ scatters between 1000 and $3500 \mathrm{~m} . \mathrm{s}^{-1}$. Figure $10 \mathrm{a}, \mathrm{b}$ clearly shows that there is no direct relationship between plug and outcrop measurements, an observation that points to a scale effect. Indeed, outcrop measurements take into account greater scales of heterogeneities than plug measurements, including the impact of interfaces at the outcrop scale (e.g. cracks, fractures, Figure 4). 

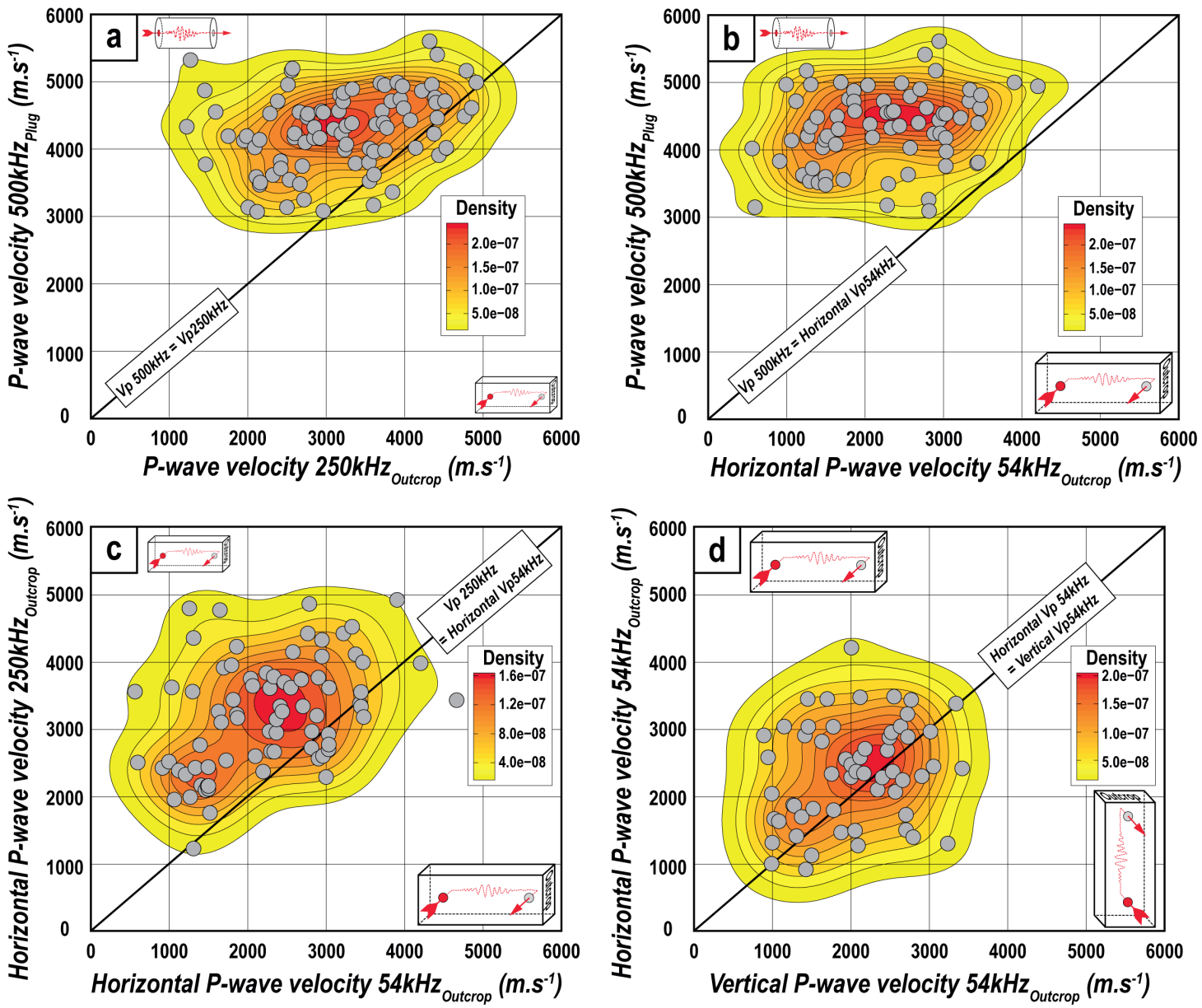

Figure 10. Comparison of $\mathrm{P}$-wave data acquired at the outcrop and laboratory with probability density maps (PDM). Line of equality between datasets are also indicated. (a) $\mathrm{Vp}_{500}$ versus $\mathrm{Vp}_{250}$. (b) $\mathrm{Vp}_{500}$ versus $\mathrm{Vp}_{54 \mathrm{H}}$. (c) $V \mathrm{p}_{250}$ versus $V \mathrm{p}_{54 \mathrm{H}}$. (d) $V \mathrm{p}_{54 \mathrm{H}}$ versus $V \mathrm{p}_{54 \mathrm{~V}}$.

Further findings at the outcrop scale are highlighted with the Figure 10c which compare $\mathrm{Vp}_{250}$ with $\mathrm{Vp}_{54}$. In this plot, the major part of the dataset exhibits $\mathrm{Vp}_{250}$ higher than $\mathrm{Vp}_{54 \mathrm{H}}$ with a few data points located close to the line of equality. Moreover, despite the scattering of the dataset, the PDM shows a linear trend that mimics the line of equality, suggesting that $\mathrm{Vp}_{250}$ and $\mathrm{Vp}_{54 \mathrm{H}}$ are sensitive to the same features. This result goes hand in hand with the previous observations made in Figure 10a, b, cracks and fractures affect mainly the elastic properties of outcrop measurements. Finally, the Figure $10 \mathrm{~d}$ compares $\mathrm{Vp}_{54 \mathrm{H}}$ with $\mathrm{Vp}_{54 \mathrm{~V}}$ acquired at outcrop on the same locality. Despite the scattering of the dataset, the highest values of PDM are around the line of equality, indicating an almost elastic isotropy. This finding denotes that the defects affecting the elastic properties of outcrop scale are almost randomly distributed. 


\section{Discussion: Upscaling of physical properties in carbonates}

\subsection{Insight through the pore compressibility evolution from plug scale to outcrop scale}

We use a simple effective medium model to determine the evolution of the pore compressibility

373 with scale: from plug to outcrop, assuming a homogeneous, isotropic and dry medium. According to the

374 Mori-Tanaka scheme, Benveniste (1987) shows that the effective bulk modulus, $K_{\text {eff, }}$ is related to the

375 porosity, $\Phi$, the bulk modulus of the pore-free matrix, i.e. the bulk modulus of the calcite $\left(K_{0}=71 \mathrm{GPa}\right)$

376 and the pore compressibility $(P)$ is normalized to the compliance of a spherical pore (David and

377 Zimmerman, 2011a):

$$
\frac{K_{0}}{K_{\mathrm{eff}}}=1+\frac{\Phi}{(1-\Phi)} P\left(v_{0}\right)
$$
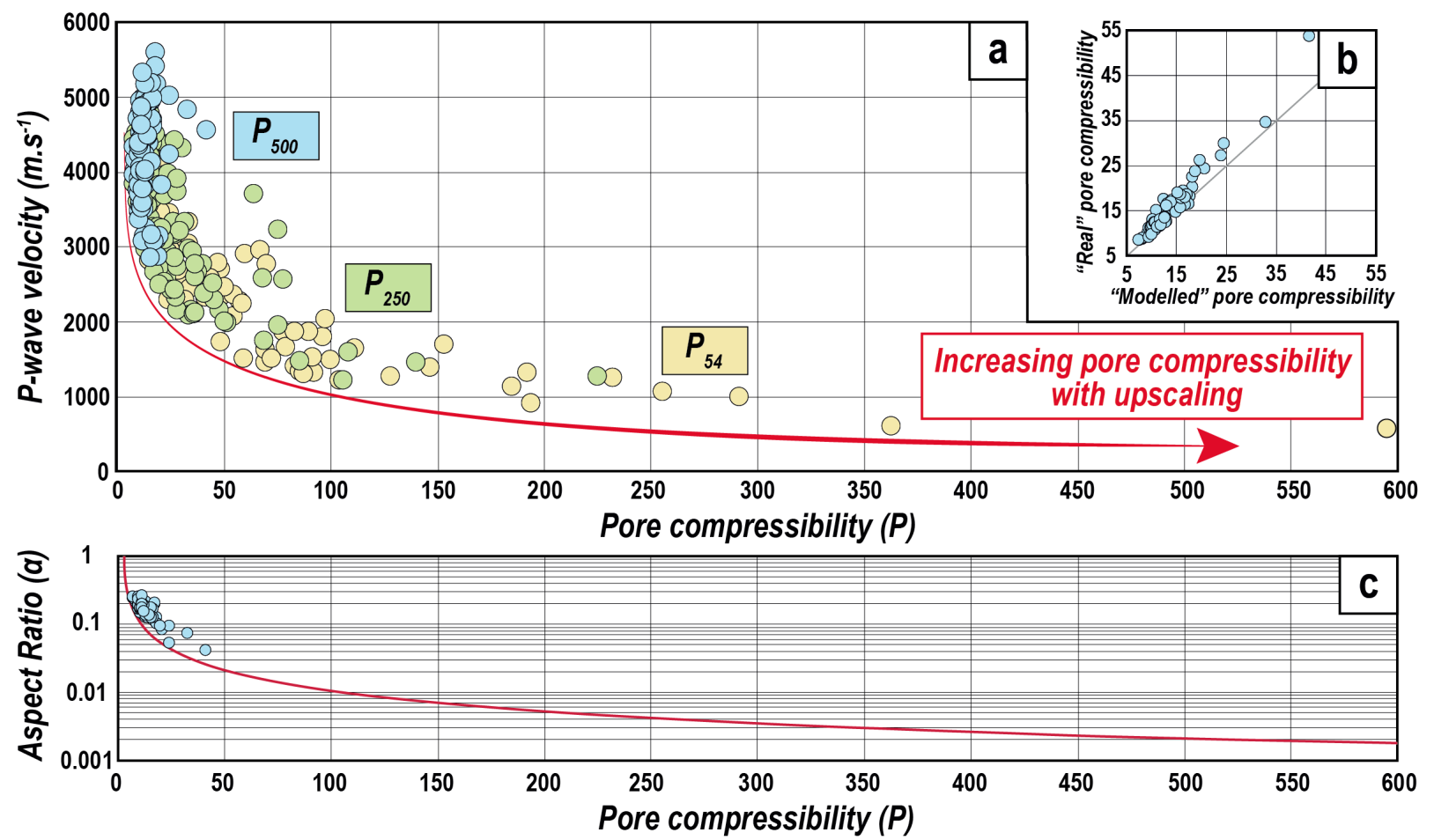

Figure 11. Pore compressibility control on $P$-wave velocity. (a) P-wave velocity versus pore compressibility for three datasets calculated for a Poisson ratio of 0.29. (b) Real versus modelled pore compressibility for ultrasonic laboratory data. (c) Relationship between aspect ratio and pore compressibility for a calcite medium (red line calculated for an equivalent ellipsoidal pore). The blue dots represent the aspect ratio determined for spheroidal pores at the plug scale (Figure $7 \mathrm{~b}$ ). 
386 (2) and (3):

$$
\begin{gathered}
V_{p}^{2}=\frac{K_{\mathrm{eff}}+\frac{4}{3} G_{\mathrm{eff}}}{\rho_{b}}, \\
V_{s}^{2}=\frac{G_{\mathrm{eff}}}{\rho_{b}},
\end{gathered}
$$

where $\rho_{b}$ is the density of the studied medium. At the plug scale, Vp, Vs and $\Phi$ are measured. Using equations (2) and (3) one can compute the effective bulk modulus, and then compute the pore compressibility at plug scale $\left(P_{500}\right)$, using equation (1). Results are plotted in Figure 11a (dots in blue) and show values for $P_{500}$ between 12 and 17. Poisson ratio $(v)$ obtained at plug scale is constant whatever the scale. At the plug scale, $V_{p} / V_{s}=1.84$, 394 leading to $v_{\text {eff }}$ equal to 0.29 , a value close to the one of a pure calcite mineral ( $\left.v_{\text {Calcite }}=0.31\right)$. Equations (2) 395 and (3) can be combined to get :

$$
K_{\mathrm{eff}}=\frac{V_{p}^{2} \rho_{b}}{1+4\left(\frac{1-2 v_{\mathrm{eff}}}{2+2 v_{\mathrm{eff}}}\right)}
$$

396 At the plug scale, the comparison of the "real" pore compressibility $P$ (i.e. the one calculated by using $V_{p}$ 397 and $V_{s}$ data) and the one calculated under the assumption that $v_{\text {eff }}$ is constant and equal to 0.29 ("Modelled 398 pore compressibility" in Figure 11b) aims to show that the "modelled" $P$ is slightly underestimated, i.e. 399 under the assumption that $v_{\text {eff }}$ is constant, pores appear slightly stiffer than they are in reality (Figure 11b).

400 We also assume that there is no significant porosity change between the plug and the outcrop scale, which 401 is a valid approximation, as the porosity of the plugs are in the range $10-30 \%$ and at larger scale the 402 additional porosity due to the cracks and fractures is expected to be $\leq 3 \%$. Thus, we can use the set of 403 equations (1) and (4) to compute the pore compressibility at an outcrop. 
The P-wave velocity acquired at plug and outcrop are plotted versus their associated pore compressibility (Figure 11a). Results show that there is an increase of the pore compressibility with 407 upscaling, implying a softening of the porous network from laboratory scale to outcrop scale (porous 408 medium containing more and more compressible/soft pores, e.g. cracks). Indeed, from $\mathrm{Vp}_{500}$ to $\mathrm{Vp}_{54}, P$ 409 increases and can reach values up to 600. The Figure 11a shows that for P-wave values range between 1000 410 and $2000 \mathrm{~m} \cdot \mathrm{s}^{-1}$, the associated $P$ values tend to be higher than 50-100 (threshold value). According to David 411 and Zimmerman (2011a), we can relate $P$ with the aspect ratio $(\alpha)$ of an equivalent ellipsoidal pore. We use 412 their asymptotic approximations to compute an "effective" aspect ratio for a given $P$ (red curve of 413 Figure 11c). For plug data, the equivalent aspect ratios calculated using the model of David and Zimmerman 414 (2011a) are slightly lower than the effective aspect ratios previously obtained with DEM modeling (David 415 and Zimmerman, 2011b). Comparing the threshold value observed on Figure 11A ( $P$ around 50-100) with 416 the Figure 11C allows us to conclude that upscaling from the plug to outcrop scale is characterized by an 417 addition of very soft pores $(\alpha<0.01$, cracks). These very soft pores may be linked with the structural 418 features observed on the outcrop (Figure 4).

\subsection{Upscaling modeling of elastic properties, from ultrasonic to seismic frequencies}

As stated before, the upscaling of elastic properties in carbonates need to take into account different

423 geological scales (Figure 1). Using an effective medium model, it is possible to model the evolution of P424 wave velocity with scale, as described by the Figure 12. 


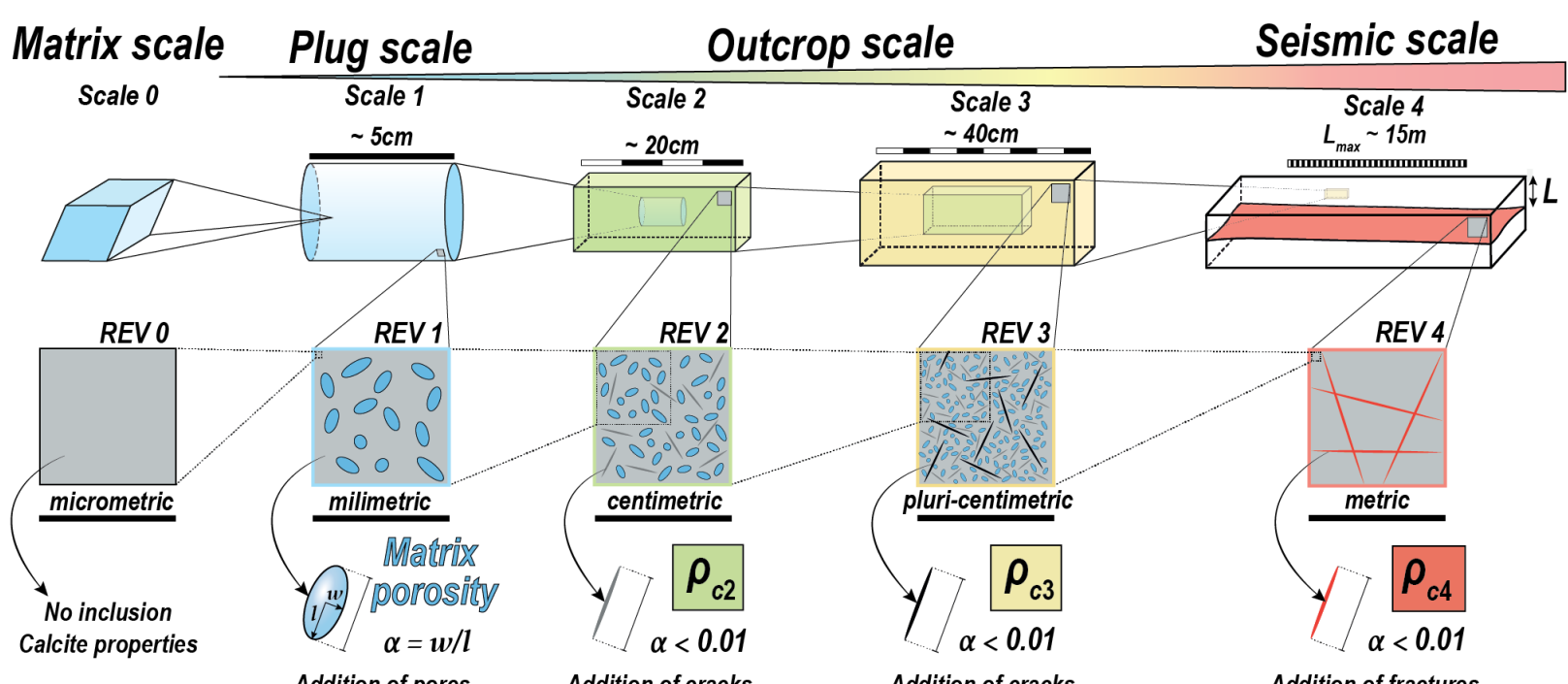

426

427

428

429

430

431

432

433

434

435

436

437

438

439

440 441 Nevertheless, the aspect ratio obtained, at plug scale, are representative of a small REV containing

442 millimetric pores, and are not necessarily equal to the one of a larger volume (Figures 8, 9, 10 and 11).

Figure 12. Modeling of the elastic properties at different scales by adding pores $(0.01<\alpha<0.3)$ and cracks/fractures $(\alpha<0.01)$ of different sizes relating to the REV.

At the matrix scale, the elastic properties of the medium are equal to the one of a pure calcite mineral $\left(\mathrm{K}_{0}=\mathrm{K}_{\text {calcite }}=71 \mathrm{GPa}, \mathrm{G}_{0}=\mathrm{G}_{\text {calcite }}=30 \mathrm{GPa}\right.$; Mavko et al., 2009). Then, at plug scale, the elastic properties $\mathrm{K}_{1}, \mathrm{G}_{1}$ are assumed to be the one of a calcite matrix containing spheroidal pores of a given equivalent aspect ratio. These elastic properties are computed employing the asymptotic expressions given by David and Zimmerman (2011b). In Figure 7b, the obtained results show that most of the plug-scale data corresponds to an aspect ratio between 0.1 and 0.2 , a range close to the reference of carbonates $\left(\alpha_{\text {ref }} \sim 0.15\right)$ given by Xu and Payne (2009) and Fournier et al. (2018) who also used DEM modeling. This first step of inverting P-wave velocity and porosity data in terms of equivalent pore aspect ratio is now widely used in the literature (e.g. Baechle et al., 2008; Fournier et al., 2011, 2014, 2018; Regnet et al., 2019a; Xu and Payne, 2009). It aims to explain the scattering of P-wave velocity for a given porosity and is of crucial importance for reducing the uncertainties in inverting and interpreting seismic data (Eberli et al., 2003). 
445 a low aspect ratio $(\alpha<0.01$, Figure 11) related to the cracks/fractures observed in the field (Figure 4). We

446 can use the crack density $\left(\rho_{c}\right)$ defined by Walsh (1965) for quantifying the amount of circular cracks at

447 different scales (Figure 12, equation 5):

$$
\rho_{c}=\frac{1}{V} \sum_{i=1}^{n} c_{i}^{3},
$$

$448 \rho_{c}$ is the crack density for $n$ cracks of radius $c$ in a volume $V$. Following David and Zimmerman (2011b), 449 asymptotic solutions for the DEM in the case of crack-like pores $(\alpha<0.01)$ give us expressions of the 450 effective moduli $K$ and $G$ as explicit functions of $\rho_{c}$ :

$$
\begin{gathered}
\frac{K_{i+1}}{K_{i}}=\frac{\left(1-2 v_{i}\right) e^{-\frac{16}{9} \rho_{c}}}{1-2 v_{i} e^{-\frac{8}{5} \rho_{c}}}, \\
\frac{G_{i+1}}{G_{i}}=\frac{\left(1+v_{i}\right) e^{-\frac{16}{9} \rho_{c}}}{1+v_{i} e^{-\frac{8}{5} \rho_{c}}}
\end{gathered}
$$

451 where $K_{\mathrm{i}}, G_{\mathrm{i}}$ and $v_{\mathrm{i}}$ are the effective elastic moduli of the lower scale $(\mathrm{i}=1,2,3)$. Note that in the set of 452 equations 6 and 7, we remove the previous assumption of constant Poisson ratio that was only used to 453 compute pore compressibilities. In the following, the plug scale $\left(\mathrm{Vp}_{500}\right)$ corresponds to the scale 1 (REV 1 454 of Figure 12), the first outcrop scale $\left(\mathrm{Vp}_{250}\right)$ corresponds to the scale 2 (REV 2 of Figure 12), the second 455 outcrop scale $\left(\mathrm{Vp}_{54}\right)$ corresponds to the scale 3 (REV 3 of Figure 12$)$ and the seismic scale $\left(\mathrm{Vp}_{100}\right)$ 456 corresponds to the scale 4 . As an exemple, for the upscaling from scale 1 to scale $2: K_{l}$ and $G_{l}$ are taken as 457 the median value deduced from the data obtained on plugs $\left(\mathrm{Vp}_{500}\right) ; \mathrm{K}_{2}$ is taken as the median value deduced 458 from the data obtained on outcrop $\left(\mathrm{Vp}_{250}\right)$; then, using equation 6 and 7 , one can compute the crack 459 density $\rho_{c 2}$ (Figure 13).

Figure 13 shows the calculated $\rho_{c i}$ between scales based on the median values of P-wave velocities 462 obtained for each dataset. First, the decrease of P-wave velocity with upscaling from scale 1 to scale 2, is 
463 associated with a $\rho_{c 2}$ value of 0.27 related to the presence of cracks with a size $\leq 2 \mathrm{~cm}\left(\lambda_{250}\right.$, Figure 9$)$. The

464 resulting medium, REV2 of Figure 12, thus presents cracks $\leq 2 \mathrm{~cm}$ embedded within a porous carbonate

465 with spheroidal pores $\leq 1 \mathrm{~cm}$ characterized by an aspect ratio around $0.15\left(\alpha_{\mathrm{ref}}\right)$.

Then, the P-wave velocity decreases again with upscaling between $\mathrm{Vp}_{250}$ and $\mathrm{Vp}_{54}$. The transition

468 from scale 2 to scale 3 is linked with an addition of another crack density $\rho_{c 3}=0.3$ related to the presence

469 of cracks with size $\leq 6 \mathrm{~cm}\left(\lambda_{54}\right.$, Figure 9). The resulting medium, REV 3 of Figure 12, thus contains two

470 different scales of crack density, $\rho_{c 2}$ and $\rho_{c 3}$, embedded in a porous medium. Finally, passing from scale 3

471 to scale 4 implies again an addition of another crack density $\left(\rho_{c 4}=0.07\right)$ related to cracks/fractures of a size

$472 \leq 20 \mathrm{~m}\left(\lambda_{100}\right.$, Figure 9). The resulting REV 4 includes three different scales of cracks, $\rho_{c 2}, \rho_{c 3}$ and $\rho_{c 4}$,

473 embedded within a matrix porosity characterized by pores with an equivalent pore aspect ratio equal to

474 0.15. This multi-scale concept aims to explain the overall decrease of P-wave velocity from plug to seismic

475 scale by taking into account different scales of heterogeneities, corresponding to different REVs, that have

476 geological and physical significances (i.e. pores, cracks and fractures). It is therefore of importance for

477 understanding of the physical properties of subsurface reservoirs (i.e. fractured carbonate reservoirs). 


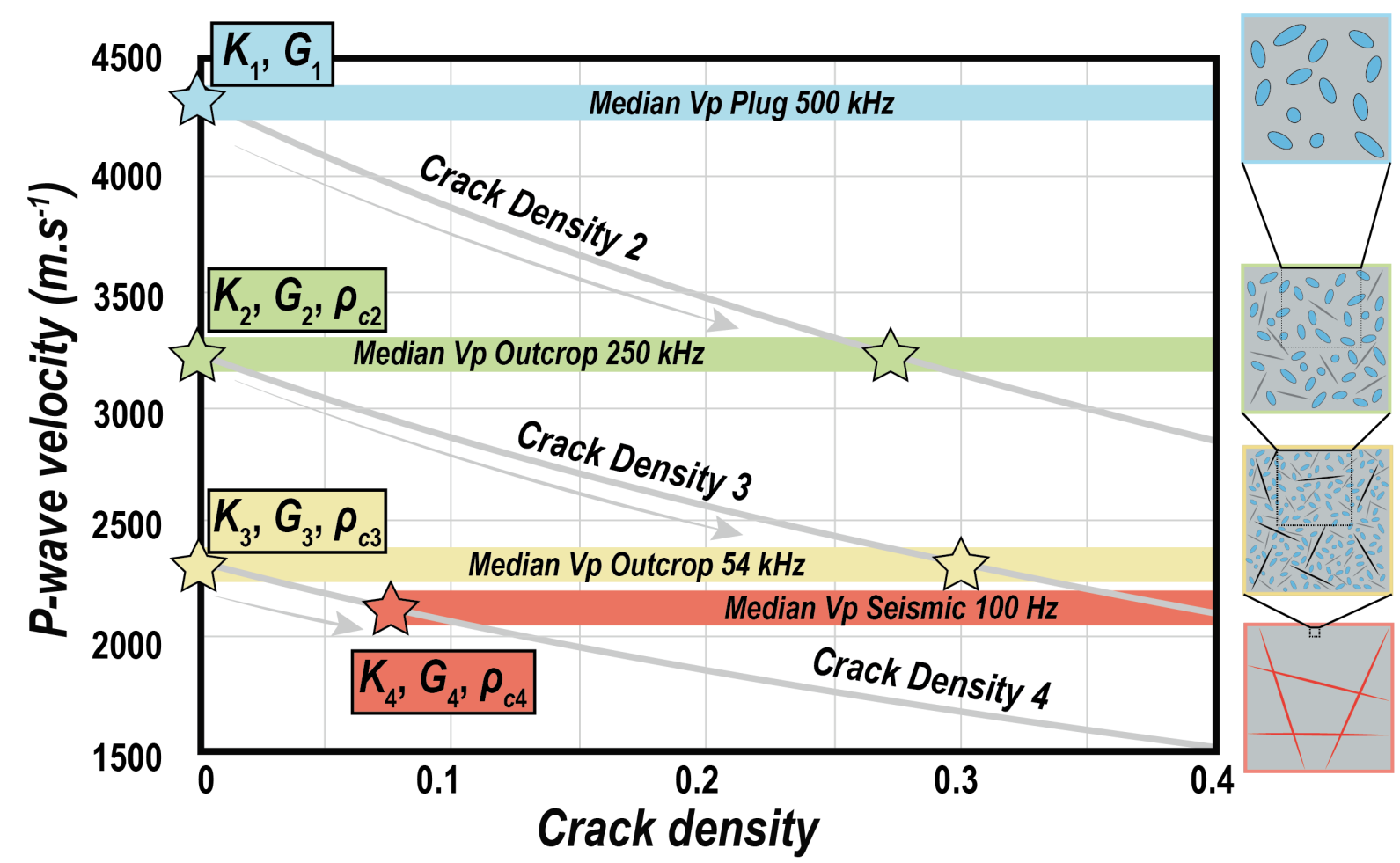

478

Figure 13. P-wave velocity versus computed crack densities for the median of each acoustic dataset.

\subsection{From elasticity to reservoir properties of carbonates, implications of the crack porosity}

As shown by several authors, reservoir properties (like porosity and permeability) are controlled by different factors (e.g. pore types and sizes) regarding the scale of investigation (Corbett, 2009; Haldorsen and Lake, 1984; Nordahl, 2004; Ringrose et al., 2008; Ringrose and Bentley, 2015). The multi-scale elastic properties obtained in this work are similar to what is found in the literature. At the lower scales of investigation (microscopic and macroscopic scales of Figure 1), the microstructure controls the physical properties of carbonates (Anselmetti and Eberli, 1993; Regnet et al., 2019b). Indeed, the microstructures present a huge diversity of sedimentary textures that may be modified by diagenetic processes, implying an important heterogeneity of their physical properties. DEM modeling shows that most of the dataset indicates an equivalent pore aspect ratio range equal to the reference value of carbonates $\left(\alpha_{\text {ref }}=0.15\right)$, despite samples present a high variability of microstructures. Then, for higher scales of investigation, the presence of large scale structural features impact the elastic properties (Figure 4). Again, using DEM modeling, we invert the 
494 P-wave velocity evolution with scale in terms of crack density, highlighting that the different scales are 495 impacted by structural features (Figures $12 \& 13$ ). Furthermore, based on the assumption that the cracks 496 and fractures have an aspect ratio equal to $10^{-3}$ (Figure 11) we can compute the crack porosity thanks to the 497 following equation (David and Zimmerman, 2011b):

$$
\Phi_{\text {crack }}=\frac{4}{3} \pi \rho_{c} \alpha_{\text {crack }}
$$

498 where $\Phi_{\text {crack }}$ is the computed crack porosity, $\rho_{c}$ is the crack density and $\alpha_{\text {crack }}$ is the crack aspect ratio (here 499 assumed to be equal to $10^{-3}$ ). Using equation (8), with the values of crack density previously obtained, 500 (Figure 13) give us a total amount of megascopic crack/fracture porosity equal to $0,27 \%\left(\Phi_{\text {crack } 2}+\Phi_{\text {crack } 3}\right.$ $\left.501+\Phi_{\text {crack }}\right)$. This value is close to the one recently obtained by Panza et al. (2019), who used a stochastic 502 approach (Discrete Fracture Network modeling based on field structural analysis) to compute the fracture 503 porosity of a $1 \mathrm{~m}^{3}$ block of tight carbonate (mean $\Phi_{\text {crack }}=0.3 \%$ ).

The estimation of the crack-fracture porosity done above is computed using the median Vp value for each dataset. We can also compute "local" crack porosity for scales 2 and 3. For example for scale 2, 507 ( $\mathrm{i}=1$, in equation 6 and 7) we can use the plug values for $\mathrm{K}_{1}$, and $\mathrm{K}_{2}$ from local log measurement (instead 508 of using the median value of the dataset), then we can compute local crack/fracture porosity. Figure 14 509 shows the dataset for scales 1, 2 and 3 in a velocity-porosity plot. As expected before with the Figure 10a, b, 510 the primary control of matrix porosity on the P-wave velocity tends to be lost with upscaling (Figure 14). 511 Indeed, for the scale 2, almost all $\mathrm{Vp}_{250}$ values are lower than the $\alpha_{\mathrm{ref}=0.15}$ curve (Figure $14 \mathrm{~b}$ ). In the upper 512 part of the PDM, most of the dataset presents $\Phi_{\text {crack }}$ values lower than $0,1 \%$ and tends to mimic the matrix 513 trend. In the lower part of the PDM, the scattering increases and is associated with an increasing $\Phi_{\text {crack }}$ (up

514 to $0,6 \%$ ). For the scale 3 , all $\mathrm{Vp}_{54}$ values are lower than the $\alpha_{\text {ref }=0.15}$ curve (Figure $14 \mathrm{c}$ ). The highest velocity 515 values shown in the PDM do not highlight any links between P-wave velocity and porosity. Furthermore, 516 for medium porosity (between 10 and $20 \%$ ), the Figure $14 \mathrm{c}$ shows a huge fluctuation of P-wave velocity 517 (between 3500 and $1000 \mathrm{~m} \cdot \mathrm{s}^{-1}$ ) associated with an increase in $\Phi_{\text {crack }}$ (from 0,1 to $0,6 \%$ ). The progressive 

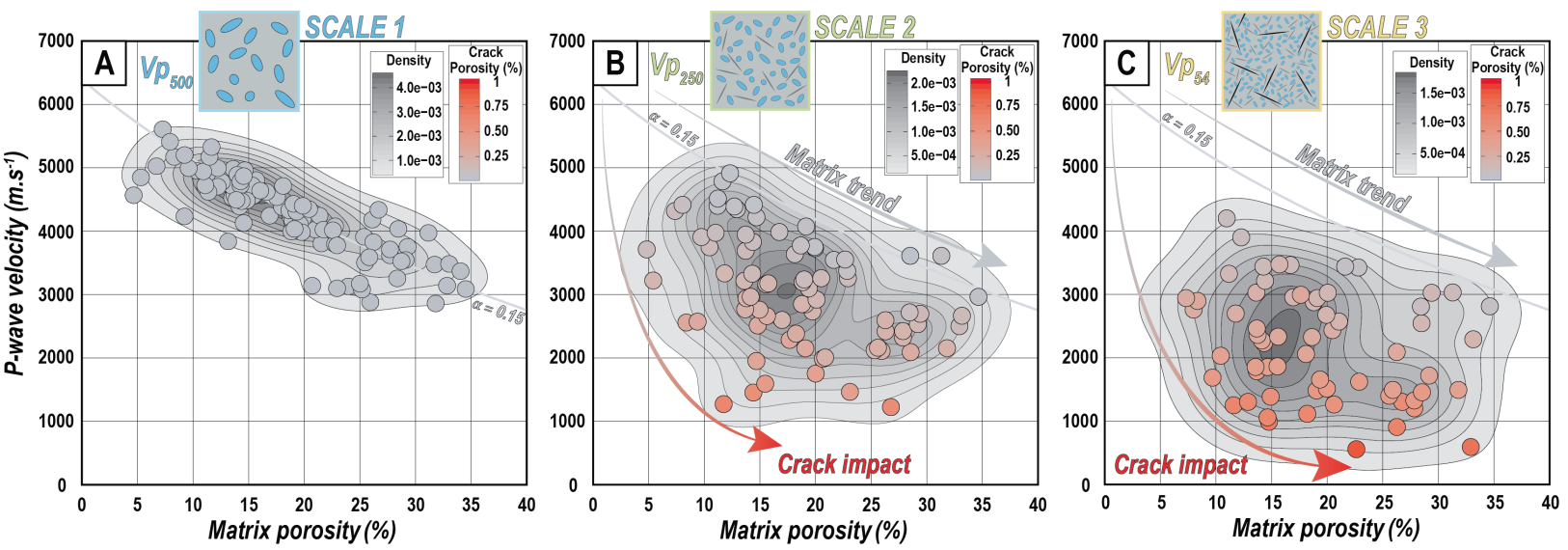

Figure 14. Impact of the crack density/porosity on the elastic properties. (a) P-wave velocity $(500 \mathrm{kHz})$ versus matrix porosity (i.e. plug porosity). The grey dots indicate the data obtained at plug scale that follow the curve of equivalent $\alpha=0.15$ without crack porosity. (b) P-wave velocity $(250 \mathrm{kHz})$ versus matrix porosity with curves of constant crack porosity. The colored dots indicates the inverted crack porosity value for all the data $\left(\Phi_{\text {crack } 2}\right)$. (c) P-wave velocity $(54 \mathrm{kHz})$ versus matrix porosity with curves of constant crack porosity. The colored dots indicates the inverted crack porosity value for all the data $\left(\Phi_{\text {crack } 2}+\Phi_{\text {crack } 3}\right)$. $($ Grey dots $=$ no crack porosity; red $=$ crack porosity of $1 \%)$.

\subsection{How to define the elastic properties of carbonates at different scales?}

associated major controlling factors (porosity of the matrix, cracks and fractures). In order to be representative of a medium, the geological interpretation of an elastic measurement needs to be within the constraints of the REV size ( $\lambda$, Figure 15a) which depends on i) the tool frequency $(f)$ and ii) the P-wave velocity (v) using the well-known relationship : $\lambda=\mathrm{v} / f$. Following the theory of homogenization, the upper limit size of an elastic REV has to be lower than the wavelength size induced by the used geophysical tool. Conversely, by analogy with seismic investigation, the lower limit of an elastic REV has to be higher than the quarter wavelength size (Sheriff and Geldart, 1995). Indeed, this resolution corresponds to the minimum 
interval between two interfaces to be seen as two separate objects and not a single one, it therefore can be

544 used as the minimum size of an elastic REV (Al-Chalabi, 2014). Furthermore, as defined by Sheriff (2002),

545 the detectable limit in seismic is "the minimum thickness for a bed to give a reflection that stands out above

546 the background". It has a size equal to a thirtieth of the wavelength size (Sheriff and Geldart, 1995).

Between ultrasonic $(\sim \mathrm{MHz})$ and seismic $(\sim \mathrm{Hz})$ measurements, the change of frequency implies a 549 variation of wavelength size, from millimetric to metric (Figure 15a). This upscaling implies a change of 550 the characterized geological object. At plug scale ( $5 \mathrm{~cm}$ of investigation, blue zone of Figure 15$)$, the P551 wave velocity is lower than the velocity of calcite and fluctuates because of the intrinsic variability of matrix 552 porosity composed of micro/millimetric pores (Figure 15b). It has to be noted that the fluctuations observed 553 in this dataset are related to the variation of the total porosity and the pore shapes, as already suggested by 554 several authors (Anselmetti and Eberli, 1993; Eberli et al., 2003; Fortin et al., 2007; Soete et al., 2015; 555 Fournier et al., 2018; Regnet et al., 2019a, b). Then, the upscaling to the outcrop scale $2(\sim 20 \mathrm{~cm}$ of 556 investigation for the green zone of Figure 15) is again associated with a decrease of the P-wave velocity. 557 Indeed, for that scale, the fluctuations of the P-wave velocity (Figure 15b) are controlled by both the crack 558 and matrix porosity (Figures $14 \mathrm{~b}$ and $15 \mathrm{c}, \mathrm{d}$ ). Going a step further with measurements at the outcrop scale 3 559 ( $\sim 40 \mathrm{~cm}$ of investigation for the yellow zone of Figure 15$)$ aims to highlight this conclusion. The P-wave 560 velocity decreases because of an increasing crack-related porosity. These "scale effects" were already 561 pointed out by Matonti et al. (2015) who also attribute the upscaled P-wave velocity decrease to the 562 occurrence of outcropping structural features. Finally, at the seismic scale 4, the pluri-metric REV 4 563 highlights P-wave velocities is slightly lower than outcrop scale 3, implying that another scale of crack 564 porosity materialized by metric fractures and bedding planes. Despite this slight difference, the mean P565 wave velocity of the outcrop scale 3 is very close to the one acquired at seismic scale (Figure 15b), 566 suggesting that a medium of $40 \mathrm{~cm}$ in length is representative of the seismic scale. This finding is of 567 importance for upscaling procedures because it shows that sonic measurements (here of $54 \mathrm{kHz}$ ) may better 
568 correspond to seismic velocities (here of $100 \mathrm{~Hz}$ ), while ultrasonic measurements on plugs and outcrops

569 (respectively of $500 \mathrm{kHz}$ and $250 \mathrm{kHz}$ ) do not fit with seismic acquisition.

This brings the usual question of the representativeness of plug measurements for reservoir

572 characterization (Ringrose et al., 2008; Corbett et al., 2015). Indeed, by analogy, several authors show that

573 multi-scale geological medium implies different fluid-flow properties that has to be related to multiscale

574 REVs (Nordahl \& Ringrose, 2008; Ringrose et al., 2008; Corbett, 2009; Claes, 2015; Ringrose and

575 Bentley, 2015). Similarly here, the upscaling of elastic properties of lacustrine carbonates shows that we

576 need to take into account several scales of rock heterogeneities, from microscopic to megascopic scales,

577 including pores, cracks and fractures, following thus the early works of Stierman and Kovach (1979) as

578 well as Moos and Zoback (1983). The present work highlights the need to interpret and model multiscale

579 elastic data with regards to the different length scales related to geology (Figures 1 and 12). This is of

580 importance for linking high frequency and low frequency elastic moduli because an elastic wave with

581 different frequencies will not necessarily characterize the same geological object. This fact goes against the

582 assumption often made that the drained moduli (equal to the dry elastic moduli) is the same whatever the

583 frequency. Indeed, the geological medium is not homogeneous with scale, implying that it does not 584 necessarily have the same multi-scale elastic properties (Figure 15). 


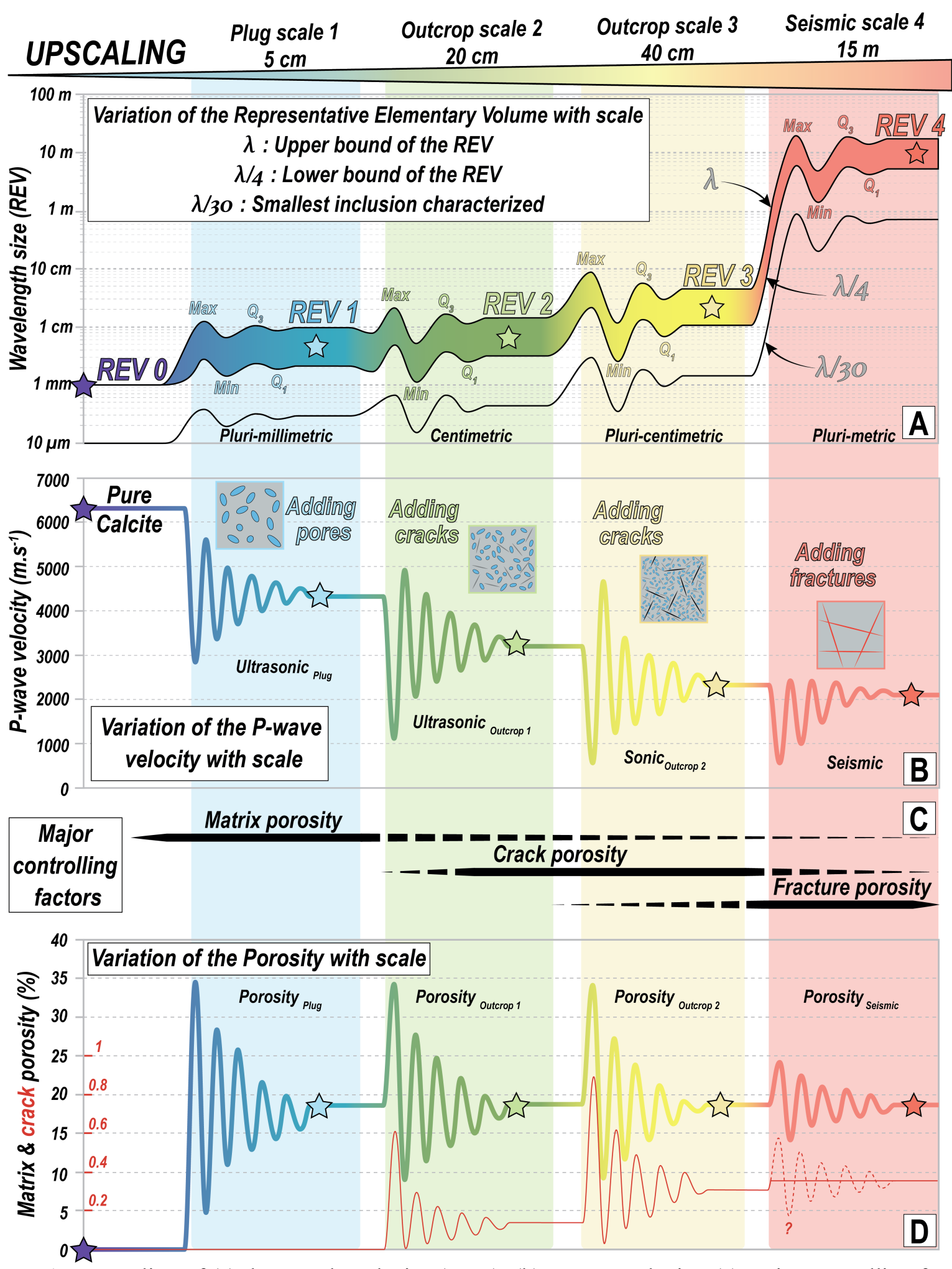

Figure 15. Upscaling of (a) the wavelength size (REV), (b) P-wave velocity, (c) major controlling factors and (d) porosity versus arbitrary scale of measurements. The curve starts from the pure calcite value and fluctuates with scale changes. For the REV, the descriptive statistics introduced in Figure 9 are used to symbolize the variability. Then, for P-wave velocity and porosity, each fluctuation of the curve represents $10 \%$ of the dataset (deciles), until arriving on the median value symbolized by a plateau. 


\section{Conclusion}

This multi-scale geophysical characterization enables the linkage of elastic properties of

595 dry lacustrine carbonates to relative proportions of crack/fracture porosity. If upscaling of the elastic

596 properties is largely discussed in the literature, there is a paucity of multi scale acoustic field datasets.

597 Indeed, the originality of this work is to compare different scales of acoustic measurements, from ultrasonic

598 to seismic frequency, acquired on the same geological object, keeping in mind the size of the elastic REV

599 - the wavelength size - induced by the used geophysical tools. The large dataset acquired at all scales allow

600 us to have an approach which is statistically effective. Results show that P-wave velocities decrease with

601 decreasing frequency, so that the acoustic measurements are related to the REV evolution and thus to the

602 size of geological features. Indeed, upscaling of elastic properties from ultrasonic (microscopic scale) to

603 seismic (megascopic scale) frequencies means increasing the REV, from pluri-millimetric to pluri-metric.

604 Furthermore, results also show that acoustic measurements done at a frequency of $54 \mathrm{kHz}(\mathrm{scale}$ of $\sim 40 \mathrm{~cm})$

605 are really close to the one acquired at $100 \mathrm{~Hz}$, suggesting that sonic velocities can be extrapolated to the

606 seismic frequencies at least for the study site that we investigated. Using effective medium theory, a model

607 based on the comparison of the multiscale datasets is presented (concept of multi-scale REVs). It aims to

608 upscale P-wave velocity assuming that inclusions with different aspect ratios $\left(\alpha_{\text {matrix }}\right.$ pores $=0.15$ and $\alpha_{\text {crack- }}$

609 fractures $=10^{-3}$ ) control the elastic behavior of the studied lacustrine carbonates. In our study, model-based

610 results suggest that the crack density/porosity becomes the main controlling factor of P-wave velocity at

611 seismic scale. Finally, the inherited different scales of geological heterogeneities (pores, cracks, fractures)

612 impact differently the elastic properties. This implies that the common matrix porosity control on ultrasonic

613 wave velocities may be lost with upscaling because of the presence of larger structural features (cracks,

614 fractures and bedding planes), a result that is of importance for the understanding of subsurface reservoir 615 properties (i.e. porosity and permeability) using solely sonic and seismic data. 
617 This work is supported by IFP Energies Nouvelles (grant XFP32/001). It is a part of the PhD project of the

618 first author, at IFP Energies Nouvelles and Laboratoire de Géologie of Ecole normale supérieure. We thank

619 Ariel Gallagher for the reviewing of the English of this manuscript. We also thank Jo Garland, an 620 anonymous reviewer and Editor Yves Bernabé for their constructive comments which helped to 621 significantly improve the manuscript.

\begin{tabular}{|c|c|c|c|c|c|c|c|c|}
\hline & \multicolumn{5}{|c|}{ Laboratory dataset } & \multicolumn{3}{|c|}{ Outcrop dataset } \\
\hline $\begin{array}{c}\text { Thickness } \\
\text { (m) }\end{array}$ & $\begin{array}{c}\text { Sample } \\
\text { name }\end{array}$ & $\begin{array}{c}\text { Density } \\
d r y\end{array}$ & Porosity & $\begin{array}{c}V p \\
d r y \\
500 \\
k H z\end{array}$ & $\begin{array}{c}\text { Vs } \\
d r y \\
500 \\
\text { Khz }\end{array}$ & $\begin{array}{c}V p \\
250 k H z \\
\text { Horizontal }\end{array}$ & $\begin{array}{l}\text { Vp } 54 \mathrm{kHz} \\
\text { Horizontal }\end{array}$ & $\begin{array}{c}\text { Vp } \\
54 k H z \\
\text { Vertical }\end{array}$ \\
\hline 0.2 & RE001 & 2.15 & 0.206 & 4192 & 2264 & 1986 & 1267 & 2090 \\
\hline 0.4 & RE002 & 2.34 & 0.137 & 4744 & 2889 & 3945 & 1793 & 1779 \\
\hline 0.6 & RE003 & 2.017 & 0.256 & 3504 & 2259 & 2160 & 1406 & 1306 \\
\hline 0.8 & RE004 & 2.34 & 0.136 & 4523 & 2752 & 2766 & 3033 & 1149 \\
\hline 1 & RE005 & 2.288 & 0.155 & 4566 & 2575 & 3161 & 1870 & 1263 \\
\hline 1.2 & RE006 & 2.164 & 0.201 & 4166 & 2451 & 2919 & 3030 & 1457 \\
\hline 1.4 & RE007 & 2.124 & 0.216 & 3802 & 2200 & 3546 & 3443 & 1449 \\
\hline 1.6 & RE008 & 2.283 & 0.157 & 4802 & 2803 & 3175 & 3478 & 2550 \\
\hline 1.8 & RE009 & 2.322 & 0.143 & 4385 & 2554 & 3328 & 3443 & 1698 \\
\hline 2 & RE010 & 2.329 & 0.141 & 4545 & 2775 & 2964 & 2278 & 2401 \\
\hline 2.2 & RE011 & 2.284 & 0.156 & 4550 & 2717 & 2660 & 2338 & 2166 \\
\hline 2.4 & RE012 & 2.334 & 0.137 & 4564 & 2743 & 2941 & 2365 & 2533 \\
\hline 2.8 & RE014 & 2.358 & 0.129 & 4959 & 2864 & 4348 & 1309 & 998 \\
\hline 3 & & & & & & 3140 & 2366 & 2067 \\
\hline 3.2 & RE015 & 2.194 & 0.19 & 4139 & 2502 & 2151 & 1489 & 2053 \\
\hline 3.4 & RE016 & 2.092 & 0.228 & 3789 & 2264 & 3373 & 3429 & 2768 \\
\hline 3.6 & & & & & & 3333 & 2412 & 3419 \\
\hline 3.8 & RE018 & 2.391 & 0.118 & 4892 & 2767 & 3333 & 2703 & 2180 \\
\hline 4 & RE019 & 2.201 & 0.188 & 4232 & 2437 & 3195 & 2881 & 2727 \\
\hline 4.2 & RE020 & 2.208 & 0.186 & 4315 & 2477 & 3774 & 2331 & 1753 \\
\hline 4.4 & RE021 & 2.14 & 0.211 & 4019 & 2333 & 4141 & 2576 & 2117 \\
\hline 4.6 & RE022 & 2.252 & 0.17 & 4234 & 2226 & 2597 & 2959 & 3014 \\
\hline 4.8 & RE023 & 2.223 & 0.181 & 4369 & 2500 & 3636 & 2064 & 2566 \\
\hline 5 & RE024 & 2.349 & 0.136 & 4709 & 2690 & 3215 & 1860 & 1278 \\
\hline 5.2 & RE025 & 2.476 & 0.083 & 5164 & 2992 & 2558 & 2902 & 890 \\
\hline 5.4 & RE026 & 1.94 & 0.285 & 3623 & 2229 & 3610 & 2549 & 1934 \\
\hline 5.6 & RE027 & 1.938 & 0.285 & 4025 & 2270 & 2090 & 1461 & 1875 \\
\hline
\end{tabular}




\begin{tabular}{|c|c|c|c|c|c|c|c|c|}
\hline 5.8 & $R E 028$ & 1.917 & 0.294 & 3749 & 2141 & 2695 & 3030 & 1775 \\
\hline 6 & & & & & & 3759 & 2901 & 1412 \\
\hline 6.2 & RE029 & 2.34 & 0.137 & 4980 & 2759 & 3690 & 2466 & 2003 \\
\hline 6.4 & RE032 & 1.86 & 0.313 & 3965 & 2292 & 3610 & 3036 & 2634 \\
\hline 6.6 & RE030 & 2,00 & 0.262 & 4172 & 2373 & 2594 & 2096 & 2340 \\
\hline 6.8 & RE031 & 1.988 & 0.267 & 4333 & 2527 & 1222 & 1308 & \\
\hline 8.2 & RE037 & 1.922 & 0.284 & 3249 & 1996 & 2717 & 2812 & 1630 \\
\hline 8.4 & RE038 & 1.844 & 0.318 & 3470 & 2049 & 2152 & 1498 & 2703 \\
\hline 8.6 & RE039 & 1.808 & 0.331 & 3482 & 2068 & 2664 & 2296 & 2904 \\
\hline 8.8 & RE040 & 2.195 & 0.191 & 4166 & 2519 & 2845 & & \\
\hline 9 & RE041 & 2.225 & 0.176 & 4528 & 2724 & 2284 & 2998 & \\
\hline 9.2 & RE042 & 2.174 & 0.2 & 4193 & 2410 & 1751 & 1518 & \\
\hline 9.4 & RE043 & 1.911 & 0.292 & 3545 & 2128 & 2532 & 1724 & 2703 \\
\hline 9.6 & RE044 & 1.957 & 0.278 & 3615 & 2142 & 2320 & 1208 & \\
\hline 9.8 & RE045 & 1.951 & 0.278 & 3712 & 2181 & 2421 & 1331 & \\
\hline 10 & RE046 & 2.296 & 0.154 & 4552 & 2509 & 1591 & & \\
\hline 10.2 & $R E 047 B$ & 1.817 & 0.329 & 3137 & 1891 & 2500 & 597 & \\
\hline 10.4 & RE048 & 1.77 & 0.346 & 3082 & 1888 & 2963 & 2817 & \\
\hline 10.6 & RE049 & 1.784 & 0.342 & 3362 & 1996 & 3846 & & \\
\hline 10.8 & RE050 & 2.181 & 0.197 & 4101 & 2419 & 2733 & & \\
\hline 11 & & & & & & 3409 & & \\
\hline 11.4 & RE053 & 2.358 & 0.133 & 3830 & 2291 & 0 & & \\
\hline 11.8 & RE054 & 2.467 & 0.093 & 4228 & 2581 & 4375 & & \\
\hline 12 & RE055 & 2.416 & 0.111 & 4690 & 2802 & 4400 & & \\
\hline 12.2 & $R E 056$ & 2.533 & 0.068 & 5016 & 2945 & 0 & & \\
\hline 12.6 & RE057 & 2.128 & 0.215 & 4235 & 2387 & 0 & & \\
\hline 12.8 & $R E 058$ & 2.29 & 0.153 & 4719 & 2719 & 0 & & \\
\hline 13.2 & RE059 & 2.175 & 0.199 & 3983 & 2364 & 3750 & & \\
\hline 13.4 & $R E 060$ & 2.207 & 0.187 & 4323 & 2677 & 2848 & & \\
\hline 13.6 & RE061 & 2.323 & 0.144 & 4871 & 2870 & 1452 & & \\
\hline 13.8 & RE062 & 2.122 & 0.218 & 4020 & 2572 & 4531 & & \\
\hline 14 & RE063T & 2.018 & 0.254 & 3910 & 2263 & 4437 & & \\
\hline 14.2 & & & & & & 3614 & 1031 & \\
\hline 14.4 & RE064 & 2.31 & 0.149 & 4473 & 2621 & 2759 & 1391 & 2794 \\
\hline 14.6 & RE065 & 2.371 & 0.127 & 4766 & 2790 & 4389 & & \\
\hline 23.4 & & & & & & 4107 & 3374 & 3340 \\
\hline 23.6 & $R E 106$ & 2.25 & 0.167 & 4608 & 2626 & 3987 & 3468 & 2118 \\
\hline 23.8 & $R E 107$ & 2.31 & 0.143 & 4713 & 2687 & 3830 & 2238 & 2661 \\
\hline 24 & RE108 & 2.485 & 0.073 & 5601 & 3077 & 4319 & 2946 & 2517 \\
\hline 24.2 & $R E 109$ & 2.221 & 0.182 & 4711 & 2483 & 2381 & 1121 & 1499 \\
\hline 24.4 & $R E 110$ & 1.998 & 0.263 & 3821 & 2213 & 2419 & 912 & 1426 \\
\hline 24.6 & $R E 111$ & 2.304 & 0.148 & 4958 & 2674 & 2512 & 995 & 989 \\
\hline 24.8 & RE112 & 2.371 & 0.123 & 4693 & 2800 & & & \\
\hline 25 & & & & & & 2365 & 2196 & \\
\hline 26.6 & RE066 & 2.408 & 0.114 & 4613 & 2770 & 4854 & 2785 & \\
\hline
\end{tabular}




\begin{tabular}{|c|c|c|c|c|c|c|c|c|}
\hline 26.8 & & & & & & 3431 & 1814 & 1518 \\
\hline 27 & RE067 & 2.185 & 0.194 & 4298 & 2489 & 3096 & 1662 & 1021 \\
\hline 27.2 & RE068 & 2.424 & 0.104 & 4948 & 2808 & 3745 & 2037 & 990 \\
\hline 27.4 & RE069 & 2.317 & 0.144 & 4465 & 2651 & 4415 & 3219 & 2721 \\
\hline 27.6 & RE070 & 2.376 & 0.123 & 4990 & 2613 & 4914 & 3904 & \\
\hline 28.6 & RE071 & 2.453 & 0.08 & 5403 & 2796 & 4415 & 2765 & \\
\hline 28.8 & RE072 & 2.409 & 0.112 & 4713 & 2643 & 4515 & 3330 & \\
\hline 29 & RE073 & 2.412 & 0.11 & 4933 & 2643 & 3974 & 4204 & 2006 \\
\hline 32 & & & & & & 2432 & 1496 & \\
\hline 32.2 & RE074 & 2.092 & 0.229 & 4070 & 2515 & 3257 & 1627 & 1081 \\
\hline 32.4 & RE075 & 2.154 & 0.205 & 4346 & 2538 & 3257 & 2440 & 3053 \\
\hline 32.6 & RE076 & 2.195 & 0.191 & 4430 & 2607 & 4073 & 2946 & \\
\hline 32.8 & RE077 & 2.32 & 0.141 & 4881 & 2708 & & 3337 & \\
\hline 33 & RE078 & 2.175 & 0.199 & 4391 & 2299 & 3731 & 2682 & 2466 \\
\hline 33.2 & RE079 & 2.096 & 0.226 & 4010 & 2379 & 3552 & 562 & \\
\hline 33.4 & RE080 & 1.931 & 0.288 & 3523 & 2066 & 3552 & 1297 & 3234 \\
\hline 33.6 & RE081 & 2.323 & 0.144 & 4782 & 2639 & & 2577 & 944 \\
\hline 33.8 & RE082 & 2.438 & 0.097 & 4990 & 2653 & 3906 & 1692 & 1372 \\
\hline 34.2 & RE083 & 2.46 & 0.094 & 5197 & 2809 & 2571 & & \\
\hline 34.4 & RE084 & 2.336 & 0.14 & 4488 & 2717 & 4762 & 1645 & \\
\hline 34.6 & RE085 & 2.399 & 0.116 & 5164 & 2931 & 4787 & 1255 & \\
\hline 34.8 & RE086 & 2.316 & 0.146 & 4865 & 2663 & 4219 & 1859 & \\
\hline 35 & RE087 & 2.01 & 0.259 & 3588 & 2072 & 2109 & 1498 & \\
\hline 35.2 & RE088 & 2.572 & 0.054 & 4837 & 2727 & 3221 & & \\
\hline 35.4 & & & & & & 1127 & & \\
\hline 35.6 & RE089 & 2.396 & 0.117 & 5322 & 2850 & 1270 & & \\
\hline 35.8 & RE090 & 2.276 & 0.162 & 4632 & 2521 & & & \\
\hline 36 & RE091 & 2.583 & 0.048 & 4565 & 2867 & 3712 & & \\
\hline 36.2 & & & & & & 2913 & & \\
\hline 37.2 & RE093 & 2.064 & 0.24 & 3124 & 1792 & & & \\
\hline 37.4 & RE094 & 2.088 & 0.23 & 3091 & 1888 & & & \\
\hline 37.6 & RE095 & 2.007 & 0.26 & 2877 & 1784 & & & \\
\hline 38 & RE096 & 2.094 & 0.231 & 3773 & 2026 & 1462 & & \\
\hline 38.2 & & & & & & 3425 & 4663 & \\
\hline 38.4 & & & & & & & 2872 & 2491 \\
\hline 38.6 & RE098 & 2.202 & 0.189 & 3993 & 2444 & 3236 & & \\
\hline 38.8 & RE099 & 2.318 & 0.146 & 4127 & 2390 & 1950 & 1064 & \\
\hline 39 & & & & & & 2941 & & \\
\hline 39.2 & RE101 & 2.15 & 0.208 & 3135 & 1986 & 2005 & & \\
\hline 40 & $R E 102$ & 2.029 & 0.253 & 3070 & 1736 & 2120 & & \\
\hline 40.2 & $R E 103$ & 2.036 & 0.251 & 3167 & 1886 & 3604 & 2283 & 2003 \\
\hline 40.4 & RE104 & 1.848 & 0.319 & 2859 & 1755 & & & \\
\hline 40.6 & $R E 105$ & 2.195 & 0.192 & 4025 & 2272 & & & \\
\hline
\end{tabular}

623 


\section{References}

625 Adam, L., Batzle, M., \& Brevik, I. (2006). Gassmann's fluid substitution and shear modulus variability in 626 carbonates at laboratory seismic and ultrasonic frequencies. GEOPHYSICS, 71(6), F173-F183. https://doi.org/10.1190/1.2358494

628

629

630

Adelinet, M., Fortin, J., \& Guéguen, Y. (2011). Dispersion of elastic moduli in a porous-cracked rock: Theoretical predictions for squirt-flow. Tectonophysics, 503(1-2), 173-181. https://doi.org/10.1016/j.tecto.2010.10.012

Adelinet, M., Domínguez, C., Fortin, J., \& Violette, S. (2018). Seismic-refraction field experiments on Galapagos Islands: A quantitative tool for hydrogeology. Journal of Applied Geophysics, 148, 139151. https://doi.org/10.1016/j.jappgeo.2017.10.009

Al-Chalabi, M., 2014. Principles of Seismic Velocities and Time-to-Depth Conversion, EAGE Publications, $491 \mathrm{p}$.

Anselmetti, F. S., \& Eberli, G. P. (1993). Controls on sonic velocity in carbonates. Pure and Applied Geophysics PAGEOPH, 141(2-4), 287-323. https://doi.org/10.1007/BF00998333

Baechle, G. T., Weger, R. J., Eberli, G. P., Massaferro, J. L., \& Sun, Y.-F. (2005). Changes of shear moduli in carbonate rocks: Implications for Gassmann applicability. The Leading Edge, 24(5), 507-510. https://doi.org/10.1190/1.1926808

Baechle, G. T., Colpaert, A., Eberli, G. P., \& Weger, R. J. (2008). Effect of microporosity on sonic velocity in carbonate rocks. The Leading Edge, 17, https://doi.org/10.3997/2214-4609.201404934

Bailly, C., Adelinet, M., Hamon, Y., \& Fortin, J. (2019). Combined control of sedimentology and diagenesis on seismic properties in lacustrine and palustrine carbonates (Upper Miocene, Samos Island, Greece). Geophysical Journal International, 2019, 212(2), 1300-1315. 
Bear, J. (1972). Dynamics of Fluids in Porous Media, 784 pp., American Elsevier Publishing Compagny, New York.

Benveniste, Y. (1987). A new approach to the application of Mori-Tanaka's theory in composite materials. Mechanics of Materials, 6(2), 147-157. https://doi.org/10.1016/0167-6636(87)90005-6

Borgomano, J. V. M., Pimienta, L., Fortin, J., \& Guéguen, Y. (2017). Dispersion and attenuation measurements of the elastic moduli of a dual-porosity limestone. Journal of Geophysical Research: Solid Earth, 122(4), 2690-2711. https://doi.org/10.1002/2016JB013816

Bourbié, T., Coussy, O., \& Zinszner, B. (1987). Acoustics of porous media, Editions Technip, Gulf Publishing Company, Houston, TX (TECHNIP)

Cichostępski, K., Dec, J., \& Kwietniak, 1. (2019) Simultaneous Inversion of Shallow Seismic Data for Imaging of Sulfurized Carbonates. Minerals, 9(4), 203. https://doi.org/10.3390/min9040203

Claes, S. (2015). Pore classification and upscaling strategy in travertine reservoir rocks, $119 \mathrm{pp} ., \mathrm{PhD}$ Thesis, Katholieke Universiteit Leuven.

Corbett, P. W. M. (2009). Petroleum Geoengineering : Integration of Static and Dynamic Models, 100 pp., Society of Exploration Geophysicists, Tulsa, Ohlahoma.

Corbett, P. W. M., Hayashi, F. Y., Alves, M. S., Jiang, Z., Wang, H., Demyanov, V., et al. (2015). Microbial carbonates: a sampling and measurement challenge for petrophysics addressed by capturing the bioarchitectural components. Geological Society, London, Special Publications, 418(1), 69-85. https://doi.org/10.1144/sp418.9

David, E. C., \& Zimmerman, R. W. (2011a). Compressibility and shear compliance of spheroidal pores: Exact derivation via the Eshelby tensor, and asymptotic expressions in limiting cases. International Journal of Solids and Structures, 48(5), 680-686. https://doi.org/10.1016/j.ijsolstr.2010.11.001 
668

669

670

671

672

673

674

675

676

677

678

679

680

681

682

683

684

685

686

687

688

689

690

David, E. C., \& Zimmerman, R. W. (2011b). Elastic moduli of solids containing spheroidal pores. International Journal of Engineering Science, 49(7), 544-560. https://doi.org/10.1016/j.ijengsci.2011.02.001

Eberli, G. P., Baechle, G. T., Anselmetti, F. S., \& Incze, M. L. (2003). Factors controlling elastic properties in carbonate sediments and rocks. The Leading Edge, 22(7), 654-660. https://doi.org/10.1190/1.1599691

Fortin, J., Guéguen, Y., \& Schubnel, A. (2007). Effects of pore collapse and grain crushing on ultrasonic velocities and Vp/Vs. Journal of Geophysical Research: Solid Earth, 112(8). https://doi.org/10.1029/2005JB004005

Fournier, F., Leonide, P., Biscarrat, K., Gallois, A., Borgomano, J., \& Foubert, A. (2011). Elastic properties of microporous cemented grainstones. GEOPHYSICS, 76(6), E211-E226. https://doi.org/10.1190/geo2011-0047.1

Fournier, F., Léonide, P., Kleipool, L., Toullec, R., Reijmer, J. J. G., Borgomano, J., et al. (2014). Pore space evolution and elastic properties of platform carbonates (Urgonian limestone, BarremianAptian, SE France). Sedimentary Geology, 308, 1-17. https://doi.org/10.1016/j.sedgeo.2014.04.008

Fournier, F., Pellerin, M., Villeneuve, Q., Teillet, T., Hong, F., Poli, E., et al. (2018). The equivalent pore aspect ratio as a tool for pore type prediction in carbonate reservoirs. AAPG Bulletin, 102(7), 13431377. https://doi.org/10.1306/10181717058

Haldorsen, H. H., \& Lake, L. W. (1984). A New Approach to Shale Management in Field-Scale Models. Society of Petroleum Engineers Journal, 24(04), 447-457. https://doi.org/10.2118/10976-pa

Jeanne, P., Guglielmi, Y., \& Cappa, F. (2012). Multiscale seismic signature of a small fault zone in a carbonate reservoir: Relationships between V P imaging, fault zone architecture and cohesion. Tectonophysics, 554-557, 185-201. https://doi.org/10.1016/j.tecto.2012.05.012 
691 Marion, D., \& Jizba, D. (1997). Acoustic properties of carbonate rocks: Use in quantitative interpretation of sonic and seismic measurements, In : Palaz, I, and Marfurt, K.J., eds., Carbonate Seismology: Geophysical Developments. Society of Exploration Geophysicists, Tulsa, Ohlahoma, 75-93.

Matonti, C., Guglielmi, Y., Viseur, S., Bruna, P. O., Borgomano, J., Dahl, C., \& Marié, L. (2015). Heterogeneities and diagenetic control on the spatial distribution of carbonate rocks acoustic properties at the outcrop scale. Tectonophysics, 638(1), 94-111. https://doi.org/10.1016/j.tecto.2014.10.020

Mavko, G., Mukerji, T. ; \& Dvorkin, J. (2009) The Rock Physics Handbook: Tools for Seismic Analysis of Porous Media, 524 pp., Cambridge Univ. Press, Cambridge, U.K.

Moos, D., \& Zoback, M. D. (1983). In Situ Studies of Velocity in Fractured Belair Belt. J. Geophys. Res., $88(2), 2345-2358$.

Nordahl, K. (2004). A petrophysical evaluation of tidal heterolithic deposits: Application of a near wellbore model for reconciliation of scale dependant well data, 338 pp., $\mathrm{PhD}$ Thesis, Norwegian University of Science and Technology.

705

706

707

708

709

710
Nordahl, K., \& Ringrose, P. S. (2008). Identifying the representative elementary volume for permeability in heterolithic deposits using numerical rock models. Mathematical Geosciences, 40(7), 753-771. https://doi.org/10.1007/s11004-008-9182-4

Owen, R. B., Renaut, R. W., \& Stamatakis, M. G. (2011). Late Miocene lacustrine sedimentation in the Mytilinii Basin, Samos Island, Greece. Journal of Paleolimnology, 46(1), 151-166. https://doi.org/10.1007/s10933-011-9530-0

Panza, E., Agosta, F., Rustichelli, A., Vinciguerra, S. C., Ougier-Simonin, A., Dobbs, M., \& Prosser, G. (2019). Meso-to-microscale fracture porosity in tight limestones, results of an integrated field and 
laboratory study. Marine and Petroleum Geology, 103, 581-595. https://doi.org/10.1016/j.marpetgeo.2019.01.043

715

Raymer, L. L., Hunt, E. R., \& Gardner, J. S. (1980). An Improved Sonic Transit Time-to-Porosity Transform. In SPWLA Annual Logging Symposium, 1-13. Society of Petrophysicists and Well-Log Analysts.

Regnet, J. B., Robion, P., David, C., Fortin, J., Brigaud, B., \& Yven, B. (2015). Acoustic and reservoir properties of microporous carbonate rocks: Implication of micrite particle size and morphology. Journal of Geophysical Research: Solid Earth, 120(2), 790-811. https://doi.org/10.1002/2014JB011313

Regnet, J., Fortin, J., Nicolas, A., Pellerin, M., \& Guéguen, Y. (2019a). Elastic properties of continental carbonates: From controlling factors to an applicable model for acoustic-velocity predictions. GEOPHYSICS, 84(1), MR45-MR59. https://doi.org/10.1190/geo2017-0344.1

Regnet, J. B., David, C., Robion, P., \& Menéndez, B. (2019b). Microstructures and physical properties in carbonate rocks: A comprehensive review. Marine and Petroleum Geology. Elsevier. https://doi.org/10.1016/j.marpetgeo.2019.02.022

Ring, U., Laws, S., \& Bernet, M. (1999). Structural analysis of a complex nappe sequence and late-orogenic basins from the Aegean Island of Samos, Greece. Journal of Structural Geology, 21(11), 1575-1601. https://doi.org/10.1016/S0191-8141(99)00108-X

Ringrose, P. S., Martinius, A. W., \& Alvestad, J. (2008). Multiscale geological reservoir modelling in practice. Geological Society, London, Special Publications, 309(1), 123-134. https://doi.org/10.1144/SP309.9

Ringrose, P., \& Bentley, M. (2015). Reservoir Model Design: A Practiotioner's Guide. 249 pp., Springer Netherlands. https://doi.org/DOI 10.1007/978-94-007-5497-3 
Sheriff, R.E., Geldart, L. P. (1995). Exploration seismology, 592 pp., Cambridge University Press.

Sheriff, R. E. (2002). Encyclopedic Dictionary of Exploration Geophysics, 442 pp., Society of Exploration Geophysicists.

Soete, J., Kleipool, L. M., Claes, H., Claes, S., Hamaekers, H., Kele, S., et al. (2015). Acoustic properties in travertines and their relation to porosity and pore types. Marine and Petroleum Geology, 59, 320335. https://doi.org/10.1016/j.marpetgeo.2014.09.004

Stamatakis, M. G., Hein, J. R., \& Magganas, A. C. (1989). Geochemistry and diagenesis of Miocene lacustrine siliceous sedimentary and pyroclastic rocks, Mytilinii Basin, Samos Island, Greece. Sedimentary Geology, 64, 65-78. https://doi.org/https://doi.org/10.1016/0037-0738(89)90084-5

Stierman, D. J., \& Kovach, R. L. (1979). An in situ velocity study: The Stone Canyon Well. Journal of Geophysical Research: Solid Earth Solid Earth, 84(B2), 672-678. https://doi.org/10.1029/JB084iB02p00672

Verwer, K., Braaksma, H., \& Kenter, J. A. (2008). Acoustic properties of carbonates: Effects of rock texture and implications for fluid substitution. GEOPHYSICS, 73(2), B51-B65. https://doi.org/10.1190/1.2831935

Walsh, J. B. (1965). The effect of cracks on the compressibility of rock. Journal of Geophysical Research, 70(2), 381-389. https://doi.org/10.1029/jz070i002p00381

Wang, Z., Hirsche, W. K., \& Sedgwick, G. (1991). Seismic velocities in carbonate rocks. Journal of Canadian Petroleum Technology, 30(2), A354. https://doi.org/https://doi.org/10.2118/91-02-09

Weidmann, M., Solounias, N., Drake, R. E., \& Curtis, G. H. (1984). Neogene Stratigraphy of the Eastern Basin,. Geobios, 17(4), 477-490. 
757 Wollner, U., \& Dvorkin, J. (2018). Seismic-scale dependence of the effective bulk modulus of pore fluid upon water saturation. GEOPHYSICS, 83(2), MR81-MR91. https://doi.org/10.1190/geo20170293.1

760 Wyllie, M. R., Gregory, A. R., \& Gardner, G. H. F.. (1956). Elastic wave velocities in heterogeneous and 761 porous media, GEOPHYSICS, 21, 41-70. doi:10.1190/1.1438217

762 Xu, S., \& Payne, M. A. (2009). Modeling elastic properties in carbonate rocks. The Leading Edge, 28(1), 763 66-74. 